\title{
Computational Modeling and Sensitivity Evaluation of Liquid Rocket Injector Flow
}

\author{
Yolanda Mack, ${ }^{*}$ Raphael Haftka, ${ }^{\dagger}$ and Corin Segal ${ }^{\ddagger}$ \\ University of Florida, Gainesville, FL 32611-6250 \\ Nestor Queipo ${ }^{\S}$ \\ University of Zulia, Maracaibo, Venezuela \\ and \\ Wei Shyy ${ }^{* *}$ \\ University of Michigan, Ann Arbor, MI 48109
}

\begin{abstract}
A three-dimensional computational model of an experimental rectangular combustion chamber was developed to explore the wall heat transfer of a $\mathbf{G O}_{2} / \mathbf{G H}_{2}$ shear coaxial single element injector. The CFD model allowed for the direct analysis of heat transfer effects due to flow dynamics - an analysis that would be very difficult using experimental studies alone. The use of a 3-D CFD model revealed heat transfer effects due to flow streamlines and eddy conductivity, and provided insight into the two-dimensional nature of the wall heat flux. A grid sensitivity study was conducted to determine the effects of grid resolution on the combustion chamber length and heat flux. The results of a grid sensitivity study were inconclusive, as a grid-independent solution could not be reached. However, it was found that the predicted heat flux was largely independent of the grid resolution, as long as the near-wall region was well resolved. Finally, a single-element injector model was constructed to explore the sensitivity of the peak heat flux and combustion chamber length to the circumferential and radial spacing of injector elements in the outer row of a multi-element injector. Many cases, including the baseline case, had a recirculation region that was oriented such that the outer shear layer was directed at the combustion chamber wall, resulting in a large peak heat flux near the injector face. It was found that by increasing the spacing between injector elements of the outer row while reducing the distance of the outer row to the wall, a relatively flat heat flux profile could be obtained.
\end{abstract}

\section{Nomenclature}

$c \quad=$ heat capacity

$k=$ conduction coefficient

$\dot{m} \quad=$ mass flow rate

$q \quad=$ heat flux

$t \quad=$ time

$T \quad=$ temperature

$x=$ distance from the injector face

$y \quad=$ distance from the wall

$y^{+} \quad=$ turbulent non-dimensionalized distance from the wall

\footnotetext{
${ }^{*}$ Graduate Student Assistant, Mechanical and Aerospace Engineering Department, Student Member AIAA.

${ }^{\dagger}$ Distinguished Professor, Mechanical and Aerospace Engineering Department, Fellow AIAA.

* Associate Professor, Mechanical and Aerospace Engineering Department, Associate Fellow AIAA.

${ }^{\S}$ Professor, Applied Computing Institute, University of Zulia, Maracaibo, Venezuela.

${ }^{* *}$ Clarence L. "Kelly" Johnson Collegiate Professor and Department Chair, Department of Aerospace Engineering, Fellow AIAA. 
$\begin{array}{ll}z & =\text { Cartesian coordinate } \\ \rho & =\text { density }\end{array}$

\section{Introduction}

$\mathrm{T}$ HE combustion chamber of a liquid rocket engine is cooled by transferring heat to the unburned fuel that circulates around the outside of the combustion chamber via a series of tubes or coolant channels. Rocket injectors deliver the fuel and oxidizer to the combustion chamber. Commonly, the injector face is made up of a series of injector elements arranged in concentric rows. The row of injectors near the chamber wall can cause considerable local heating that can reduce the life of the combustion chamber. The local heating near each injector element takes the form of a sinusoidal wall heat flux profile caused by the interactions of the outer row elements. Often, this effect is not considered during the design process. Reducing the intensity of this local heating is of prime importance. For example, in the design of the Space Shuttle Main Engine (SSME), the effect of the local heating in the combustion chamber was not considered during the design process. After construction, it was discovered that hotspots along the chamber wall severely reduced the expected chamber life. This resulted in an unforeseen increase in the reusability operating costs of the engine. ${ }^{1}$ Local hotspots can even cause actual burnout of the chamber wall. ${ }^{2}$ By accurately predicting potentially detrimental phenomena in advance, it may be possible that issues such as wall burnout can be avoided. Computational fluid dynamics (CFD) modeling and validation efforts, in conjunction with the experimental data, can assist in the understanding of combustor flow dynamics, eventually leading the way to efficient CFD-based design.

Historically, injectors have been designed using experimental techniques ${ }^{3,4}$ and empirical calculations. A design was built and tested, and then improvements were made based on the results. For example, Calhoon et al. ${ }^{5}$ extensively reviewed standard techniques for injector design, including the analysis of cold-fire and hot-fire testing to study general injector characteristics. The results of these tests were used along with a number of additional multielement cold-fire tests to design the full injector. The full injector was then fabricated and tested for performance and heat flux characteristics and combustion stability. However, the experimental design techniques were insufficient to predict for many conditions that could reduce injector or combustion chamber life. For this reason, researchers have begun to employ CFD techniques to aid in injector design. For example, Liang et al. ${ }^{6}$ developed semi-empirical calculations to aid in the computer modeling of liquid rocket combustion chambers. Sindir and Lynch ${ }^{7}$ simulated a single element $\mathrm{GO}_{2} / \mathrm{GH}_{2}$ injector using an 8-species, 18 reaction chemical kinetics model with

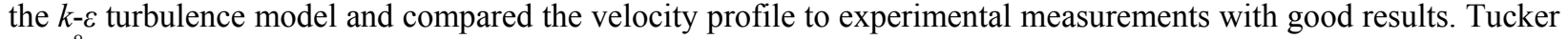
et al. ${ }^{8}$ stressed the importance of supplying experimental results to aid in the task of CFD validation.

Heating effects due to the arrangement of injector elements is of prime importance. Injector placement can result in high local heating on the combustion chamber wall. A multi-element injector face is made up of an array of injector elements. The type of elements need not be consistent across the entire injector face. The outer elements must be chosen to help provide some wall cooling in the combustion chamber. Small changes in the design of the injector and the pattern of elements on the injector face can significantly alter the performance of the combustor. ${ }^{9}$ The elements must be arranged to maximize mixing and ensure even fuel and oxidizer distribution. For example, Gill $^{10}$ found that the element diameters and diameter ratios largely influence mixing in the combustion chamber, and that small diameters lead to overall better performance. Gill suggests that using a coaxial type injector for the outer row of injectors provides an ideal environment due to the outer flow being fuel. Rupe and Jaivin ${ }^{11}$ found a positive correlation between the temperature profile along the wall and the placement of injector elements. Farhangi et al. ${ }^{12}$ investigated a gas-gas injector and measured heat flux to the combustion chamber wall and injector face. It was found that the mixing of the propellants controlled the rate of reaction and heat release. Farhangi et al. suggested that the injector element pattern could be arranged in a way that moved heating away from the injector face by delaying the mixing of the propellants.

Because of the arrangement of injector elements near the wall of the combustion chamber, the heat flux peaks near each injector element. Chamber design and potential material failure is based on peak heat flux, so the peak heat flux must be minimized to increase component life and reliability. By controlling the injection pattern, a layer of cool gas near the wall can be created. ${ }^{2}$ One method of controlling the injection pattern is to offset the oxidizer post tip away from the wall. This results in a higher percentage of unburned fuel near the wall, and this technique was used in the SSME. The cooler layer near the wall can possibly further minimize the peak heat flux. Another method of controlling the heat flux is to change the spacing of injector elements near the combustion chamber wall. This research effort looks to quantify selected geometry effects by directly exploring the sensitivity of wall heating and injector performance on the injector spacing. 
Section II presents a review of past CFD modeling and validation studies. A CFD model is constructed based on experimental results provided by Conley et al. ${ }^{13}$ that are summarized in Section III. In Section IV the CFD model is used to help understand the flow dynamics within the $\mathrm{GO}_{2} / \mathrm{GH}_{2}$ liquid rocket combustion chamber. In particular, the CFD model attempts to match the experimental heat flux data at the wall. The CFD simulation is also used to help provide answers to questions that could not be easily answered using an experiment alone. These issues include (1) the ability to show flow streamlines, (2) two-dimensional wall heat flux effects, and (3) the relationships between flow dynamics and heat flux to the combustion chamber wall. In Section V, a grid sensitivity analysis is conducted to determine the effects of grid resolution and density on wall heat flux and combustion chamber length. Finally, in Section VI, a parameter study is conducted on a CFD model that approximates an injector element near the combustion chamber wall to determine the dependence of heat flux to certain flow parameters. This parameter study analyzes the sensitivity of the wall heat flux and combustion chamber length to the outer-element injector spacing. This analysis provides background information to help guide future CFD-based design efforts.

\section{Review of Select CFD Modeling and Validation Studies}

The majority of CFD modeling and validation efforts to date have concentrated on single element coaxial injectors. Work has focused on $\mathrm{LOX} / \mathrm{GH}_{2}$ or $\mathrm{GO}_{2} / \mathrm{GH}_{2}$ combustion. Most efforts focused on matching species or velocity profiles. Only recently have efforts been in place to work towards using CFD as a combustor design tool. These recent efforts focus on accurately modeling the heat characteristics of combustors.

Liang et al. ${ }^{6}$ sought to improve the effects of multi-phase modeling that included liquid, gas, and liquid droplets. A 2-D axisymmetric model was used along with a chemical model consisting of a 9-equation kinetic model along with 4 equilibrium equations. The equilibrium equations were included to help anchor the flame during the computation by allowing for instantaneous reactions. In this case, equilibrium reactions were necessary due to the coarseness of the grid used. The turbulence model used is the eddy viscosity model. In this case, no effort is made to couple combustion with the turbulence equations. For the simulation of a gas-gas injector, a mixture fraction of unity was used for the propellants, and the combustion chamber was originally filled with oxygen. An artificial ignition region was placed near the oxygen post tip. The computation was run for a physical equivalent of $10 \mathrm{~ms}$. An attempt was made to use the 2-D model to simulate $\mathrm{LOX} / \mathrm{GH}_{2}$ multi-element injector flow by changing the walls from a no-slip to a slip boundary condition. Local peak temperature is around $2000 \mathrm{~K}$, and the average temperature is around $1500 \mathrm{~K}$. Liang et al. mentioned that, based on the CFD results, atomization might be a rate-controlling factor, but there was insufficient experimental data to confirm this fact. Liang et al. notes that grid resolution has a significant effect on flame ignition and flame steadiness, but no grid sensitivity study is conducted to explore the effects. Temperature, velocity, and mass fraction contours were obtained, but no comparison was made to experimental results, so the accuracy of the simulation is unknown.

Foust et al. ${ }^{14}$ modeled $\mathrm{GO}_{2} / \mathrm{GH}_{2}$ combustion using an 18 reaction finite-rate chemical model. The chemistry parameters were determined based on the temperature field. The k- $\varepsilon$ turbulence model was used. Preliminary computations were done to obtain the boundary conditions upstream of the injector. The final computational model extends slightly upstream of the injector exit. The model is 2 -D Cartesian, and the grid was coarse at $101 \times 51$. The computation found good agreement in the species concentration profiles and the velocity profiles. Using CFD, Foust confirmed the flame holding ability of the oxidizer post tip over wide ranges of equivalence ratios for a given injector.

Cheng et al. ${ }^{15}$ looked to develop a CFD spray combustion model to help understand the effects on wall erosion. The Finite Difference Navier-Stokes (FDNS) solver used a k- $\varepsilon$ model with wall functions, and the real fluids models were used for the multi-phase flow. Heat and mass transfer between phases was neglected. The velocity and species concentrations were solved based on a constant pressure assumption, and then the density and temperature ere determined based on the real fluids model. The pressure was then corrected based on the newly determined density. Finite-rate and equilibrium chemistry models were used. $\mathrm{The}_{\mathrm{GO}} / \mathrm{GH}_{2}$ computation used the 4-equation equilibrium chemistry model for hydrogen-oxygen combustion. The shear layer growth was well predicted by the model. Good comparisons were made between the CFD and experiment for velocity and species profiles. Disagreement in the $\mathrm{H} 2 \mathrm{O}$ species profile was attributed to experimental measurement error. It is assumed that the grid was twodimensional, however, no grid information is provided.

Schley et al. ${ }^{16}$ compared the Penn State University (PSU) code used by Foust et al. ${ }^{14}$ and the NASA FDNS code used by Cheng et al. ${ }^{15}$ with a third computational code called Aeroshape 3D (AS3D) ${ }^{17}$. The purpose in the CFD development was to reduce combustor development time and costs. The CFD computations were all based on the experiment performed by Foust et al. Schley noted that the experimental combustion chamber had a square crosssection with rounded corners, while all three research groups chose to treat it as an axisymmetric computational 
domain. None expected the non-asymmetry to impact the comparison, as other errors were thought to be more significant. The FDNS and AS3D codes included the nozzle in their computations, while the PSU code did not. The FDNS code did not include any upstream injector analysis, while the others did at least some simulation of the flow within the injector. All three codes used the k- $\varepsilon$ turbulence model. Coarse grids were used, as the researchers found that the solution increased in unsteadiness with increasing grid resolution. Despite the different codes used and the different treatments in boundary conditions, all computations agreed reasonably with each other and the experiment.

Ivancic et al. ${ }^{18}$ used the AS3D code to do simulate LOX/GH2 combustion using a coaxial shear injector. Ivancic et al. assumed chemical equilibrium for the combustion modeling with no coupling between turbulence and chemistry. A real gas model was used for the oxygen. An adaptive grid was used with 150,000 grid elements and was grid independent based on finer meshes. The simulated shear layer thickness and the flame location were not consistent with the experimental results. It is suggested that the discrepancy is due to the 2-D simulation of 3-D effects. Another reason for the discrepancy was the overly simplified combustion model.

Lin et al. ${ }^{19}$ specifically investigates the ability of CFD to predict wall heat flux in a combustion chamber for a shear coaxial single element injector based on the experimental results from the test case RCM- 1 of the $3^{\text {rd }}$ Rocket Combustion Modeling (RCM) Workshop held in Paris, France in March, 2006. Lin et al. uses the FDNS code introduced by Cheng et al. ${ }^{15}$ The model was simulated using two codes: FDNS, a finite-volume pressure-based solver for structured grids, and loci-CHEM, a density-based solver for generalized grids. The FDNS code has long been used by NASA for reacting flow simulation, but is cumbersome to use for complex geometries. Loci-CHEM, on the other hand, is a new code that is still in development. Because it is applicable to structured or unstructured grids, loci-CHEM is convenient for complex geometries. The code used a 7-species, 9-reaction finite rate hydrogenoxygen combustion model. The computational grid encompassed the pre-injector flow, combustion chamber, and nozzle. Computations are 2-D axisymmetric, and consisted of coarse grids with 61,243 points using wall functions, or fine grids with 117,648 points where the turbulence equations were integrated to the wall using Mentor's baseline model. The mass flow rates are fixed at the inlet to the computational zone with a uniform velocity profile. The experimental temperature profile is applied along the wall of the computational domain. The computational domains were initially filled with steam, and for the Loci-CHEM code, an ignition point was specified. The best matching of the heat flux values came by using the loci-CHEM code integrated to the wall using Mentor's model. Prediction of the heat flux was good in the recirculation zone and poor beyond the reattachment point. Lin et al. cited the need for additional validation and improved turbulence models to improve results.

Thakur and $\mathrm{Wright}^{20}$ tested the code loci-STREAM against the same RCM-1 test case used by Lin et al. ${ }^{19} \mathrm{~A}$ 2-D axisymmetric model was used for the computational domain. A 7-species, 9-reaction finite rate hydrogen-oxygen combustion model was used. The CFD model was initiated with steam filling the combustion chamber. Similarly to Lin et al., different grids were investigated: a fine grid with 104,000 grid points and a coarse grid with 26,000 points for integrating the turbulence equations to the wall, and a grid with 104,000 points that remains coarse near the combustion chamber wall to use with wall function formulations. The maximum chamber temperature was $3565 \mathrm{~K}$. The pressure was found to be approximately constant from the injector inlet to the nozzle throat. Thakur and Wright found that the use of wall functions lowered the predicted heat flux at the wall, regardless of whether the grid was fine or coarse. It is suspected that this may be due to errors in the computational code, as this same phenomenon was corrected in Lin et al. It was also determined that the wall heat flux was not sensitive to the grid distribution far from the combustion chamber wall, as long as the flame region is well resolved. 
Table 1. Selected CFD injector studies. All studies were based on shear coaxial injectors.

\begin{tabular}{|c|c|c|c|c|c|c|c|c|}
\hline Author & $\begin{array}{l}\text { Propel- } \\
\text { lants }\end{array}$ & $\begin{array}{l}\text { P } \\
\text { (MPa) }\end{array}$ & $T(K)$ & Summary & $\begin{array}{l}\text { Grid } \\
\text { spec. }\end{array}$ & $\begin{array}{l}\text { Turbulence } \\
\text { model }\end{array}$ & $\begin{array}{l}\text { Chemistry } \\
\text { modeling }\end{array}$ & Accuracy \\
\hline \multirow[t]{2}{*}{$\begin{array}{l}\text { Liang et } \\
\text { al. }^{6}\end{array}$} & $\begin{array}{l}\mathrm{LOX} / \\
\mathrm{GH}_{2}\end{array}$ & 0.1 & $\begin{array}{l}94.4 / \\
298\end{array}$ & \multirow{2}{*}{$\begin{array}{l}\text { Developed } \\
\text { analytical } \\
\text { equations for } \\
\text { use in } \\
\text { computer } \\
\text { simulations }\end{array}$} & \multirow[t]{2}{*}{$\mathrm{N} / \mathrm{R}$} & \multirow[t]{2}{*}{$\begin{array}{l}\text { Eddy- } \\
\text { viscosity }\end{array}$} & \multirow{2}{*}{$\begin{array}{l}\text { Finite-rate, } \\
\text { equilibrium, } \\
\text { no } \\
\text { turbulence } \\
\text { coupling }\end{array}$} & \multirow{2}{*}{$\begin{array}{l}\text { Unknown } \\
\text { (no exper. } \\
\text { data, no grid } \\
\text { refinement } \\
\text { study) }\end{array}$} \\
\hline & $\begin{array}{l}\mathrm{GO}_{2} / \\
\mathrm{GH}_{2}\end{array}$ & 0.1 & $\begin{array}{l}298 / \\
298\end{array}$ & & & & & \\
\hline \multirow[t]{2}{*}{$\begin{array}{l}\text { Foust et } \\
\text { al. }{ }^{14}\end{array}$} & \multirow[t]{2}{*}{$\begin{array}{l}\mathrm{GO}_{2} / \\
\mathrm{GH}_{2}\end{array}$} & \multirow[t]{2}{*}{1.3} & \multirow[t]{2}{*}{297} & \multirow[t]{2}{*}{$\begin{array}{l}\text { Compared } \\
\text { velocity and } \\
\text { species } \\
\text { distributions }\end{array}$} & $\begin{array}{l}\text { 2-D } \\
\text { Cartesian } \\
\text { to throat }\end{array}$ & \multirow[t]{2}{*}{ k-epsilon } & \multirow[t]{2}{*}{ Finite-rate } & \multirow[t]{2}{*}{$\begin{array}{l}\text { Good, given } \\
\text { experimental } \\
\text { velocity } \\
\text { matching }\end{array}$} \\
\hline & & & & & $\begin{array}{l}101 \times 51 \\
\text { nodes }\end{array}$ & & & \\
\hline \multirow[t]{2}{*}{$\begin{array}{l}\text { Cheng } \\
\text { et al. }^{15}\end{array}$} & $\begin{array}{l}\mathrm{LOX} / \\
\mathrm{GH}_{2}\end{array}$ & 3.1 , & $\begin{array}{l}117 / \\
309,\end{array}$ & \multirow{2}{*}{$\begin{array}{l}\text { Velocity, and } \\
\mathrm{H} 2 / \mathrm{O} 2 \text { species } \\
\text { concentration } \\
\text { validation }\end{array}$} & $\begin{array}{l}\text { 2-D, } \\
\text { axisym. }\end{array}$ & \multirow{2}{*}{$\begin{array}{l}\mathrm{k} \text {-epsilon } \\
\mathrm{w} / \text { wall } \\
\text { functions }\end{array}$} & \multirow[t]{2}{*}{$\begin{array}{l}\text { Finite-rate, } \\
\text { equilibrium }\end{array}$} & \multirow{2}{*}{$\begin{array}{l}\text { Good, given } \\
\text { experimental } \\
\text { velocity } \\
\text { matching }\end{array}$} \\
\hline & $\begin{array}{l}\mathrm{GO}_{2} / \\
\mathrm{GH}_{2}\end{array}$ & 1.3 & $\begin{array}{l}290 / \\
298\end{array}$ & & $\begin{array}{l}151 \times 81 \\
\text { nodes }\end{array}$ & & & \\
\hline $\begin{array}{l}\text { Ivancic } \\
\text { et al. }{ }^{18}\end{array}$ & $\begin{array}{l}\mathrm{LOX} / \\
\mathrm{GH}_{2}\end{array}$ & 6.0 & $\begin{array}{l}127 / \\
125\end{array}$ & $\begin{array}{l}\text { Investigation } \\
\text { of time/length } \\
\text { scales }\end{array}$ & $\begin{array}{l}2 \text {-D } \\
\text { axisym. } \\
1.5 \times 10^{5} \\
\text { elements }\end{array}$ & k-epsilon & $\begin{array}{l}\text { Equilibrium, } \\
\text { no } \\
\text { turbulence } \\
\text { coupling }\end{array}$ & $\begin{array}{l}\text { Fair, given } \\
\text { experimental } \\
\text { validation }\end{array}$ \\
\hline $\begin{array}{l}\text { Lin et } \\
\text { al. }{ }^{19}\end{array}$ & $\begin{array}{l}\mathrm{GO}_{2} / \\
\mathrm{GH}_{2}\end{array}$ & 5.2 & $\begin{array}{l}767 / \\
798\end{array}$ & $\begin{array}{l}\text { Heat flux } \\
\text { comparison for } \\
\text { flow from } \\
\text { preburner }\end{array}$ & $\begin{array}{l}\text { 2-D } \\
\text { axisym. } \\
61,243- \\
117,648 \\
\text { points }\end{array}$ & $\begin{array}{l}\text { k-epsilon } \\
\text { w/ Mentor } \\
\text { baseline } \\
\text { model }\end{array}$ & Finite-rate & $\begin{array}{l}\text { Fair, given } \\
\text { experimental } \\
\text { heat flux } \\
\text { data }\end{array}$ \\
\hline $\begin{array}{l}\text { Thakur } \\
\text { and } \\
\text { Wright }^{20}\end{array}$ & $\begin{array}{l}\mathrm{GO}_{2} / \\
\mathrm{GH}_{2}\end{array}$ & 5.2 & $\begin{array}{l}767 / \\
798\end{array}$ & $\begin{array}{l}\text { Heat flux } \\
\text { comparison for } \\
\text { flow from } \\
\text { preburner }\end{array}$ & $\begin{array}{l}\text { 2-D } \\
\text { axisym. } \\
26,000- \\
104,000 \\
\text { points }\end{array}$ & $\begin{array}{l}\text { k-epsilon, } \\
\text { w/ Mentor } \\
\text { shear stress } \\
\text { transport } \\
\text { model }\end{array}$ & Finite-rate & $\begin{array}{l}\text { Fair, given } \\
\text { experimental } \\
\text { heat flux } \\
\text { data }\end{array}$ \\
\hline
\end{tabular}

\section{Experimental Summary}

The modeling exercise is based on the experimental setup by Conley et al. ${ }^{13} \mathrm{~A}$ GH2/GO2 coaxial shear injector was investigated to examine the heat flux to the combustion chamber wall for the use of CFD validation. The experimental setup included a window for optical access and the ability to measure heat flux, temperature, and pressure in the combustion chamber. In the experiment, Conley et al. investigated the effects of combustion chamber length, pressure, and mass flow rate on the heat flux to the wall.

The injector itself was constructed of an outer hydrogen tube with an oxygen tube within. A combustion chamber with a square cross-section was used to allow for a window to be placed on the combustion chamber. The cross-sectional geometry and dimensions are given in Figure 1. The edges of the square combustion chamber were rounded to reduce stress on the chamber due to pressure.

The combustion chamber is allowed to cool between tests. Conley et al. determined in a preliminary analysis that the temperature along the combustion chamber wall would reach a maximum of $450 \mathrm{~K}$ after 10 seconds of combustion. It was estimated that the actual wall temperature reached up to $600 \mathrm{~K}$. For a similar CFD simulation, this would mean that the combustion chamber wall would be considerably cooler than the bulk flow, where the 
flame temperature can reach upwards of $3000 \mathrm{~K}$. Thus, the presence of the thermal boundary layer plays a significant part in the estimation of the heat flux via CFD.

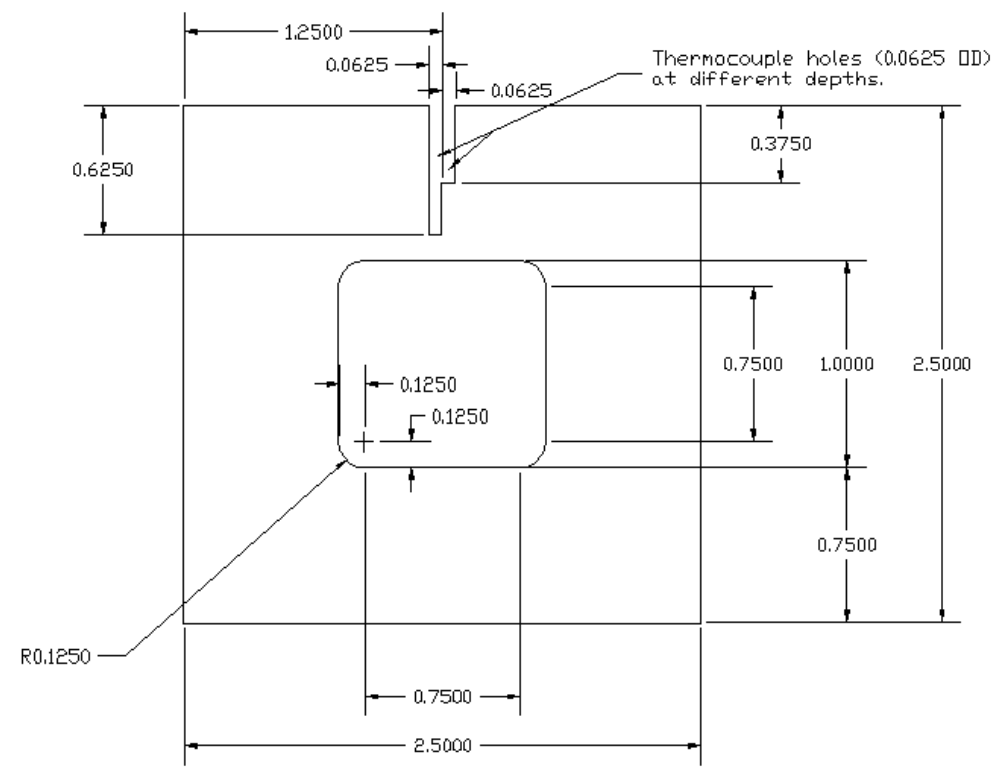

Figure 1. Combustion chamber cross-sectional geometry and thermocouple locations. ${ }^{13}$ Units are given in inches.

No temperature measurements are taken directly at the combustion chamber wall. Instead, equations were used to extrapolate temperature and heat flux values to the combustion chamber wall. The heat flux is measured along one of the combustion chamber walls and is determined using sensors that measure the temperature at two nearby locations, as shown in Figure 1. The heat flux equation was calculated based on the time-dependent experimental results to account for the unsteady effects of heat transfer.

$$
q_{\text {linear }}=\frac{k}{\Delta y}\left(T_{i, 2}-T_{o, 2}\right)+\frac{\rho c \Delta y}{2} \frac{\left(T_{o, 2}-T_{o, 1}\right)}{\Delta t}
$$

where the subscript $i$ denotes the thermocouple location closest to the combustion chamber wall and $o$ denotes the outer thermocouple location. The subscripts 1 and 2 represents an initial and final time, respectively, while $\Delta y$ is the distance between the thermocouple holes as shown in Figure 1. The material properties are for Copper 110. The chamber wall temperatures were estimated using the heat flux data and the thermal conductivity of the wall.

$$
T_{\text {wall, linear }}=\frac{q_{\text {linear }} \Delta y}{k}+T_{i}
$$

Equations (1) and (2) assume that the heat flow is one-dimensional. For a square duct, the one-dimensional linear assumption may not be correct. The actual equation would need to be determined through a numerical solution of the two-dimensional heat conduction equation. The correct heat flux equation would change the experimentally documented values of heat flux at the wall. However, because at each cross section only two temperature measurements are made, there is not enough data to do a full two-dimensional analysis of heat transfer through the combustion chamber wall. Additional temperature measurements taken within the wall would be required for an accurate estimation of wall heat flux. Therefore, a one-dimensional axisymmetric approximation was included in addition to the one-dimensional linear approximation. The 1-D axisymmetric unsteady heat flux and temperature equations are given respectively by 


$$
\begin{gathered}
q_{\text {axisymm }}=\frac{k \Delta T}{y_{\text {wall }} \ln \left(y_{o} / y_{i}\right)}+\frac{\rho c \Delta y}{2} \frac{\left(T_{o, 2}-T_{o, 1}\right)}{\Delta t} \\
T_{\text {wall,axisymm }}=\frac{\Delta T}{\ln \left(y_{i} / y_{o}\right)} \ln \left(\frac{y_{\text {wall }}}{y_{o}}\right)+T_{o}
\end{gathered}
$$

where wall denotes a location at the combustion chamber wall, and $i$ and $o$ denote the locations of the inner and outer thermocouples, respectively.

Finally, an approximation of the wall heat flux was conducted using a numerical two-dimensional unsteady heat conduction analysis. The cross-sections at each thermocouple pair location were analyzed independently. Because the experiment lasted only seven to eight seconds, it was estimated that only negligible heat escaped through the outer combustion chamber wall. Therefore, the outer wall was assumed to be adiabatic. The inner wall heat flux, taken to be uniform along the inner combustion chamber wall, was adjusted until the computational and experimentally measured temperatures obtained at 3.15 and $9.54 \mathrm{~mm}$ from the inner chamber walls (see Figure 1), respectively, are matched. The resulting temperature contours after $7.75 \mathrm{~s}$, or the run time of the actual experiment, are given in Figure 2 for the prescribed boundary conditions for the combustion chamber cross-section at $x=84$ $\mathrm{mm}$.

Conley et al. found that the point of maximum heat release using the linear approximation is at $58 \mathrm{~mm}$ from the injector face, whereas the maximum temperature occurs further downstream at $84 \mathrm{~mm}$ from the injector face. On the other hand, the point of maximum heat release using the unsteady 2-D analysis gives a maximum heat flux at the same location as that of the maximum temperature. Conley et al. also found no dependence of the heat flux on pressure when the heat flux was scaled by the mass flow rate. Specifically, Conley found that when the heat flux could be scaled by the inlet hydrogen mass flow as $q_{\text {scaled }}=q / \sqrt{\dot{m}_{H_{2}, \text { in }}}$, the heat flux profile along the wall collapsed to a single curve for a given combustion geometry. Conley concluded from the experiments that the amount of heat flux along the combustion chamber wall was primarily a function of the combustion chamber geometry.

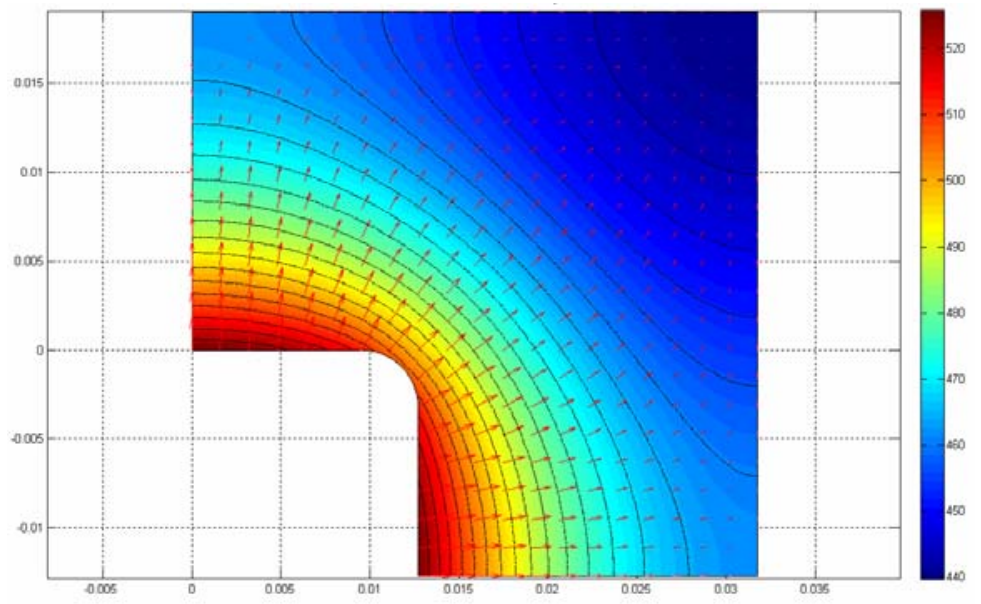

Figure 2. Temperature (K) contours for 2-D unsteady heat conduction calculations with heat flux vectors. Units are given in meters. One-quarter of the combustion chamber cross section is shown.

\section{CFD Modeling Investigation}

A CFD modeling investigation was conducted based on the experimental results presented by Conley et al. ${ }^{13}$ of a single-element shear coaxial $\mathrm{GO}_{2} / \mathrm{GH}_{2}$ injector. The CFD model is used to supplement the experimental results, and to gain insight into relevant flow dynamics. The modeling effort is particularly useful in capturing the variation of heat flux along the combustion chamber wall due to three-dimensional flow effects. 
The CFD simulations were conducted using loci-STREAM ${ }^{20}$ which is a pressure-based, finite-rate chemistry solver for combustion flows for arbitrary grids developed by Streamline Numerics, Inc. at the University of Florida. The code numerically solves the 3-D unsteady, compressible, Navier-Stokes equations. Menter's SST model is used for turbulence closure. A seven-species, nine-equation finite rate chemistry model ${ }^{21}$ was used for gaseous hydrogen and gaseous oxygen.

\section{A. CFD Model Setup}

The computational domain, grid, and boundary conditions are shown in Figure 3. The values for specific flow conditions are given in Table 2. The unstructured grid contains $1.7 \times 10^{6}$ elements and $3.7 \times 10^{5}$ nodes. The computational domain represents a three-dimensional, one-eighth-section of the full combustion chamber. No-slip conditions are specified at the combustion chamber wall, the injector face, and the oxygen post tip. Symmetry conditions are specified along the planes of symmetry and along the centerline of the combustion chamber. The nozzle is not included in the analysis; instead, a constant pressure outlet condition is specified, as the pressure is nearly constant throughout the combustion chamber. The initial temperature was set to $2000 \mathrm{~K}$ to place initial heat flux value within the range of the experimental measurements.

A short ignition region with $\mathrm{T}=3000 \mathrm{~K}$ was used in the recirculation region of the shear layer to start combustion. The ignition was turned off after the flame was self-sustaining, and the computation was run until a steady-state condition was reached based on the boundary conditions given. Applying an adiabatic condition to the combustion chamber wall was considered, but this condition would erase the thermal boundary layer along the wall. The thermal boundary layer is essential to determining the temperature gradient at the wall, and thus, the heat flux. A constant temperature condition was considered a suitable alternative, and would represent the case wherein the temperature along the wall was unknown. A constant temperature of $\mathrm{T}=500 \mathrm{~K}$ was specified along the combustion chamber wall. This temperature value was arbitrarily selected as it is within the approximate range of the experimental value, but is not equal to the average experimental temperature at the wall. Results when the experimental temperature profile is used along the combustion chamber wall are not included, as there are no obvious differences in the flow contours whether the experimental temperature profile or a constant temperature is applied at the wall. The injector face and the oxidizer post tip region between the hydrogen and oxygen inlets are set to adiabatic conditions.

Table 2. Flow conditions for CFD model.

\begin{tabular}{ll}
\hline Inlet hydrogen mass flow rate, $\dot{m}_{H_{2}}$ & $0.396 \mathrm{~g} / \mathrm{s}$ \\
Inlet oxygen mass flow rate, $\dot{m}_{\mathrm{O}_{2}}$ & $1.565 \mathrm{~g} / \mathrm{s}$ \\
Equivalence ratio, $\phi$ & 2.0 \\
Chamber pressure, $p$ & $2.75 \mathrm{MPa}$ \\
Initial combustion chamber temperature, $T$ & $2000 \mathrm{~K}$ \\
Average Mach number, $M$ & 0.04 \\
\hline
\end{tabular}




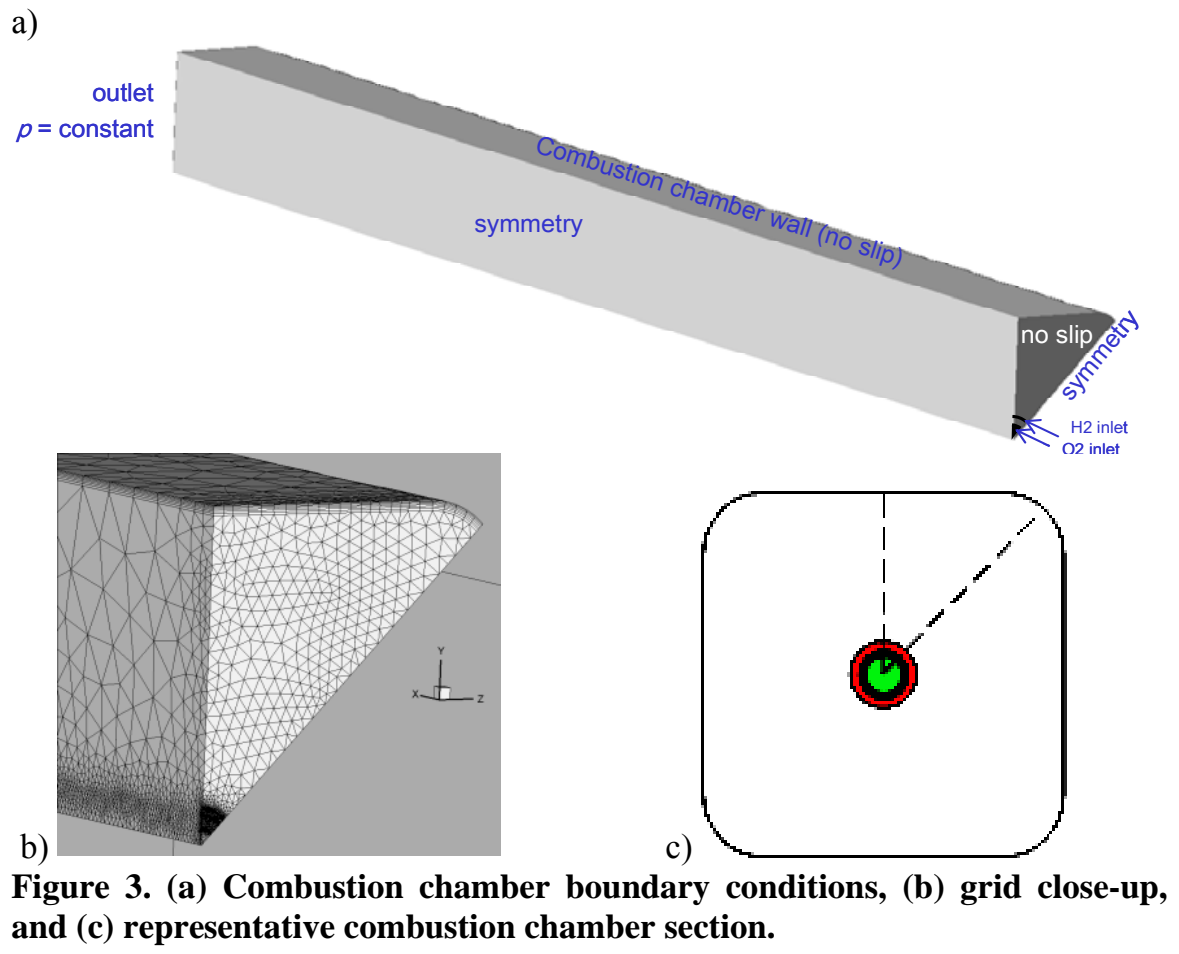

B. CFD Results and Experimental Comparison of Heat Flux

In the computation, the heat flux at a location $j$ is calculated using the following equation:

$$
q_{j, w a l l}=-k_{f l u i d} \frac{\partial T}{\partial y_{j}}
$$

The calculated heat flux based on Eq. (5) was calculated in the CFD simulation and then compared to the experimental values.

Figure 4 shows the presence of a strong recirculation region with relatively slow fluid flow. The hydrogen flow enters at a greater velocity than the oxygen flow, but quickly slows due to mixing. Due to the low Mach number of 0.04 and the relatively constant pressure throughout the combustion chamber, the density changes that occur within the combustion chamber are essentially due to changes in temperature. Figure 5 shows the temperature contours along the $z=0$ plane. The combustion length, or the distance from the injector face where $99 \%$ of the combustion is complete, is at $38 \mathrm{~mm}$.

The steady state, one-dimensional heat transfer approximation results in a linear heat flux and temperature relationship. If one accounts for the area variations via a steady state, axisymmetric treatment, then there is a different heat flux and temperature profile relationship. Finally, if one chooses to treat the outer wall boundary as adiabatic, to reflect the short experimental run time, then one can develop an unsteady, two-dimensional representation between the heat flux and the temperature distribution as described in Section III. These three cases, labeled as (i) linear one-dimensional, (ii) axisymmetric, and (iii) 2-D unsteady adiabatic are shown in Figure 6 along with the computed result. Overall, the agreement is fair. The overall trends from the CFD data and the 2-D conduction analysis are similar, but shifted. The shift in the CFD data as compared to the results of the 2-D conduction analysis indicates a faster heat release in the CFD simulation than may actually occur in the experiments. In all cases, the CFD data under-predicts the experimental data. Clearly, there are substantial uncertainties in converting limited temperature measurements within the wall to heat flux profiles on the wall. There is also uncertainty in the CFD results that may be due to the resolution of the computational domain. The effects of the grid resolution on the experimental injector element are explored in Section V. 


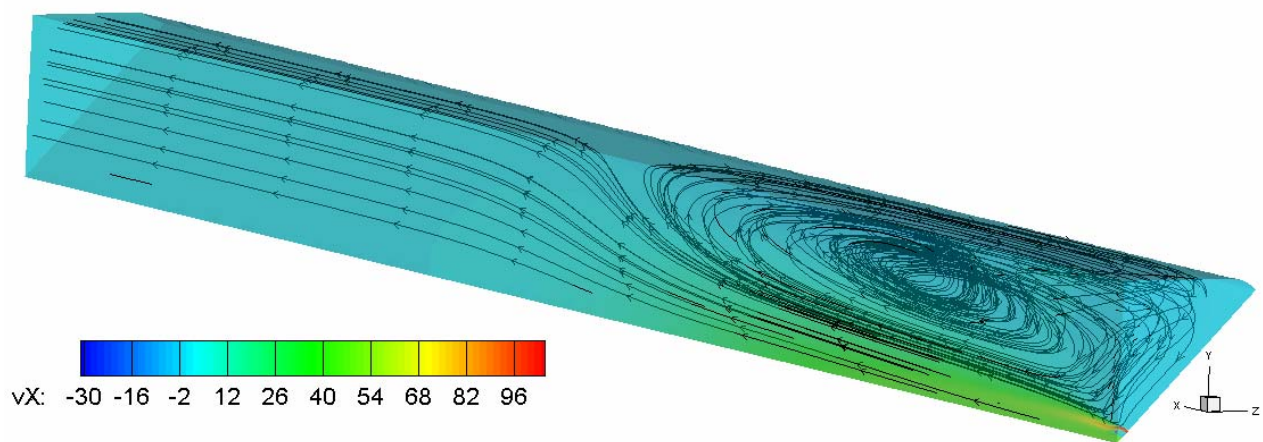

Figure 4. Velocity contours $v_{x}(\mathrm{~m} / \mathrm{s})$ and streamlines. The injector is located in the lower right corner of the combustion chamber. The reattachment point is $80 \mathrm{~mm}$ from the injector face.

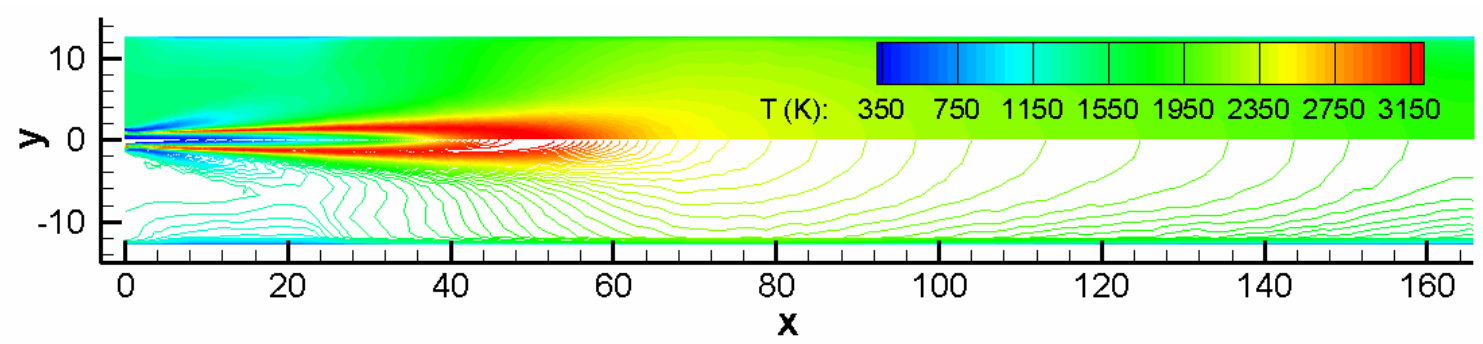

Figure 5. Temperature $(\mathrm{K})$ contours. Injector center is at $x, y=(0,0)$. Distances are given in millimeters.

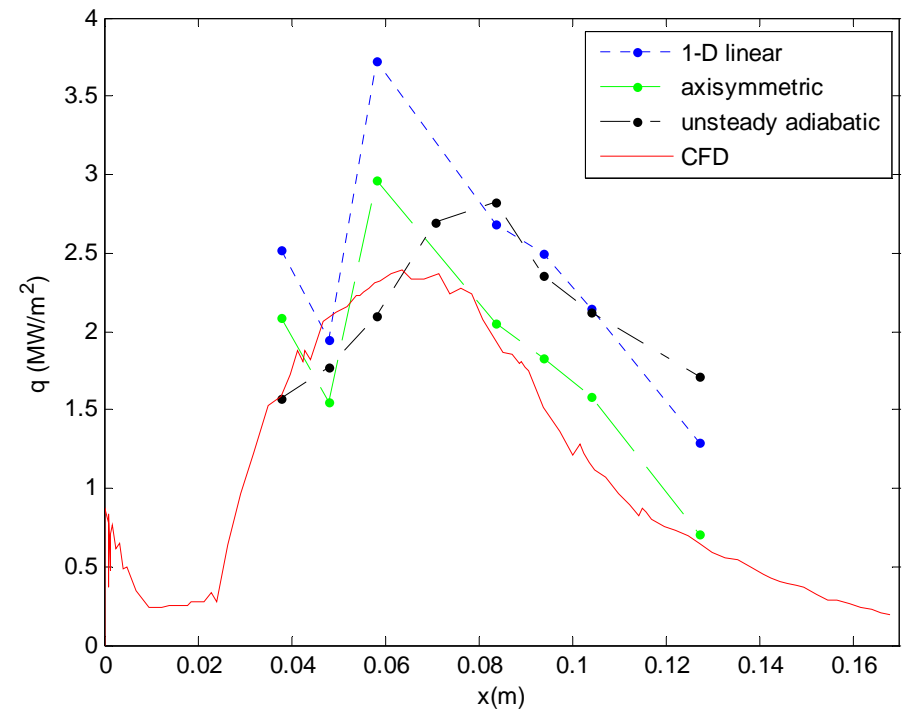

Figure 6. CFD heat flux values as compared to experimental heat flux values.

\section{Heat Transfer Characterization}

The three-dimensional simulation allows for a view of the heat flux characteristics across the flat wall. Figure 7 shows the two-dimensional nature of the predicted heat flux along the wall. Also shown in Figure 7 is the eddy conductivity. The location of peak heat flux can be clearly seen in Figure 7, and corresponds to the maximum eddy conductivity value along the combustion chamber wall. The heat flux contours show where the heated gases are circulated back towards the injector face located at the left of the plot. Additional measurements would be required for more accurate comparisons of the two-dimensional heat flux and temperature. 
Across $x=24 \mathrm{~mm}$ mark, there is a sudden jump in heat flux magnitude that corresponds to the change in $x$ velocity from positive to negative as shown in Figure 8. The sudden jump in heat flux is shown in Figure 9. The locations of stagnation region resulting from the $x$-velocity change and the streamline reattachment points are clearly apparent in the dips in the $y^{+}$values shown in Figure 9. Cooler fluid exists upstream of this stagnation region, as the approaching streamlines have come from the recirculation zone, and have had much longer residence time near the cool combustion chamber wall. This cooler fluid result is a lower heat flux to the wall between the injector face and the stagnation region. This effect can be seen along $z=0$ in Figure 9(a). The effect of the velocity change is echoed in the temperature values near the wall $\left(y^{+} \sim 2.5\right)$ as seen in Figure 10(a).

The mixing action of the shear layer transports heat from the flame to the wall. The point of maximum heat flux occurs at $63 \mathrm{~mm}$. This corresponds to the point of maximum eddy conductivity that also occurs at $63 \mathrm{~mm}$ from the injector face, shown in Figure 10(b). Similar to the experimental results, the peak wall temperature does not occur in the same location as the maximum heat flux. On the other hand, the maximum temperature along the wall occurs at $72 \mathrm{~mm}$, but is essentially constant between $64 \mathrm{~mm}$ and $79 \mathrm{~mm}$. This is immediately upstream of the reattachment point which is $80 \mathrm{~mm}$ from the injector face. The disconnection between the peak heat flux and the peak wall temperature can be related to the ratio of eddy viscosity to laminar viscosity. The wall heat flux profile corresponds to the eddy viscosity, and similarly the thermal conductivity. The temperature profile, on the other hand corresponds to the laminar, or molecular viscosity.

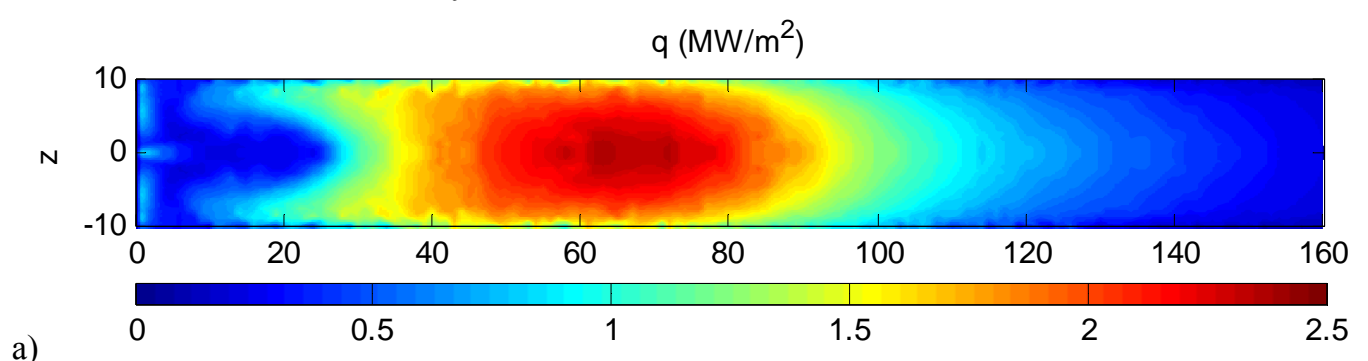

a)

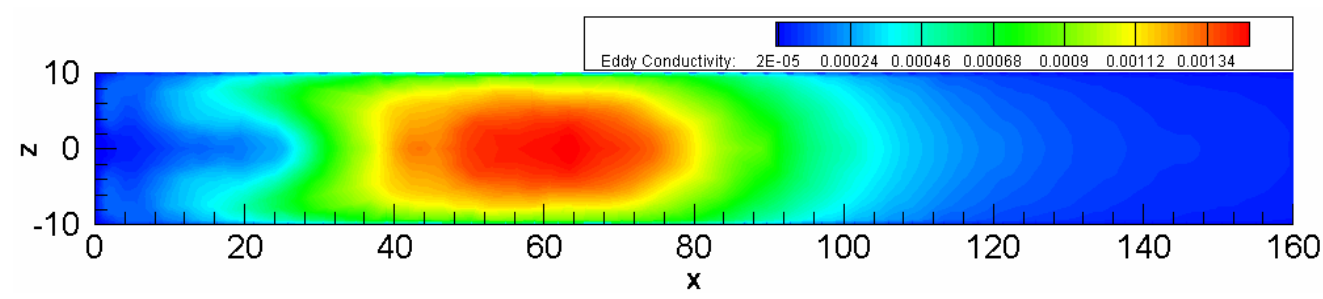

b)

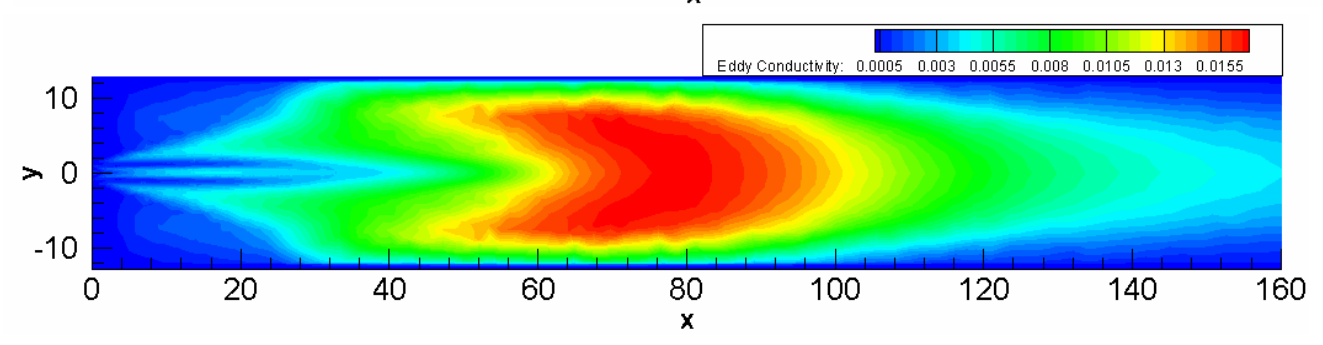

Figure 7. a) Heat flux along combustion chamber wall $(x z-$ plane at $y=12.7) b)$ eddy conductivity at $y$ $=12.3$, and c) eddy conductivity at $z=0$ with wall at $y=12.7 \mathrm{~mm}$. Eddy conductivity contours are oriented perpendicular to wall heat flux contours. Horizontal axis is $x$-axis. (Solutions mirrored across $x=0$ ). Length units are in $\mathrm{mm}$. The injector is centered at $x, y, z=(0,0,0)$, and the flow proceeds from left to right. 


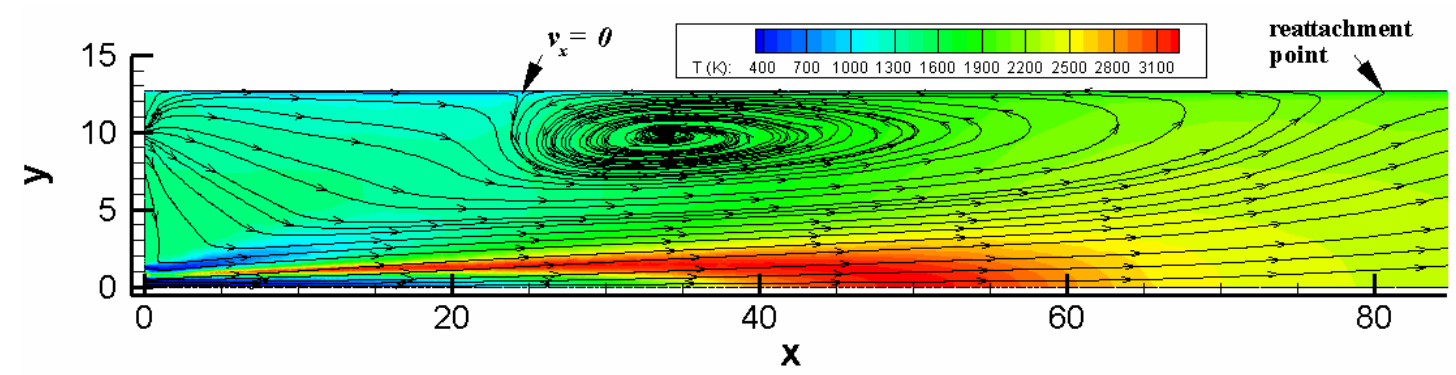

Figure 8. Streamlines and temperature contours at plane $z=0$. All lengths are in millimeters.
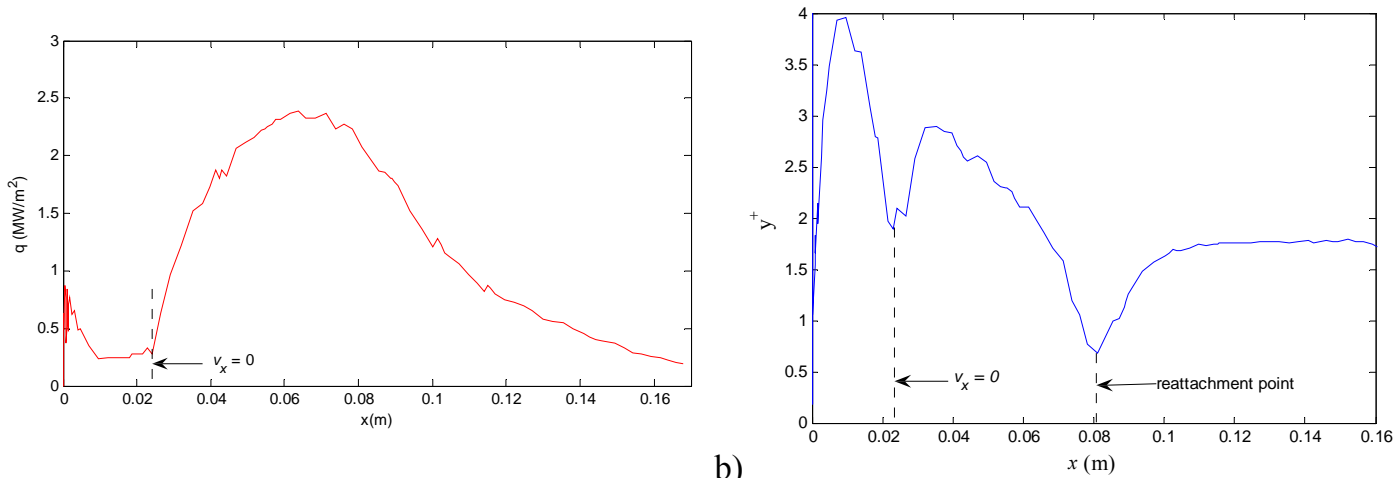

a)

b)

Figure 9. (a) Heat flux profile along the wall at $z=0$ showing sharp increase in heat flux corresponding to the location of velocity $v_{x}=0$. (b) The $y^{+}$values along the near wall cell boundary dip at stagnation regions.

a)
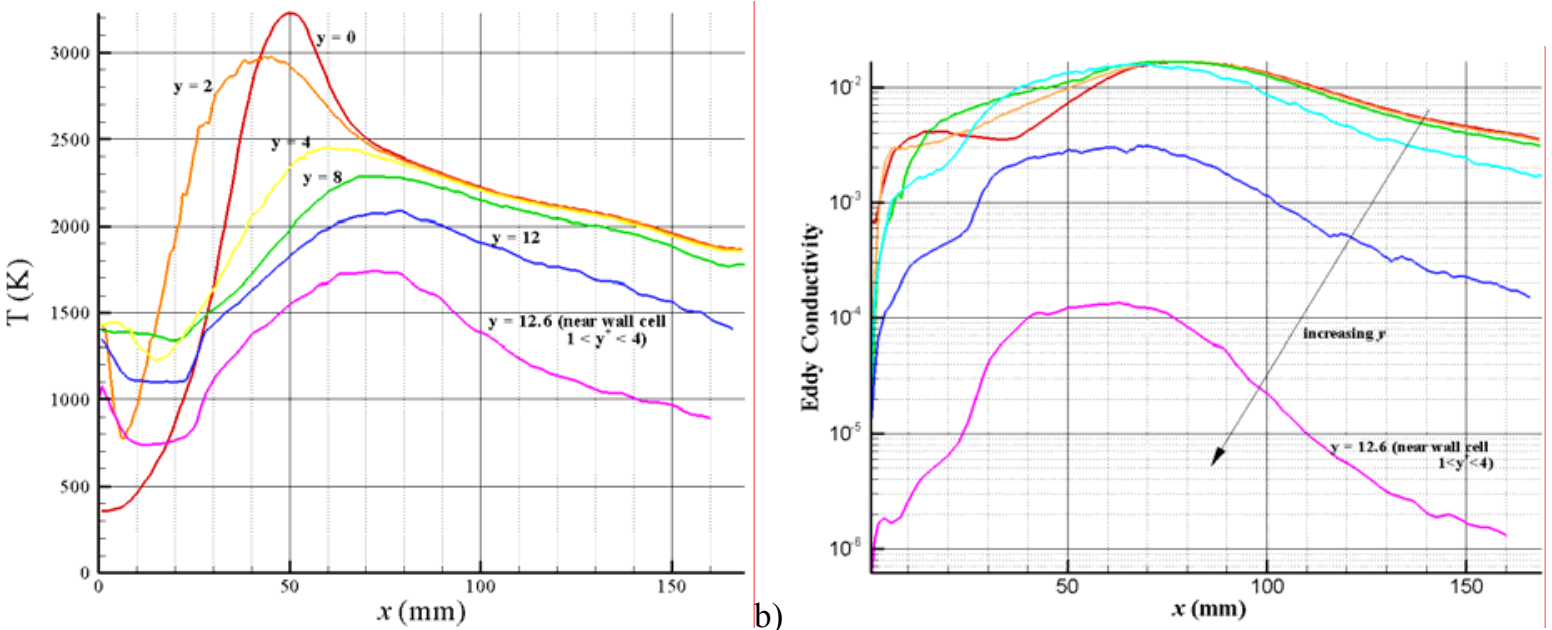

Figure 10. (a) Temperature and (b) eddy conductivity profiles at various $y$ locations on plane $z=0$.

\section{Grid Sensitivity Study}

For the grid sensitivity study, the injector element used is the same as that from the modeling study along with boundary conditions that simulate a single injector element near a combustion chamber wall. In preparation for the later parameter study in Section VI, the CFD model attempts to approximate a near-wall injector element. The subdomain is approximated using a rectangular shaped computational domain with width and height of $4.03 \mathrm{~mm}$, and a length of $100 \mathrm{~mm}$. Only one-half of the square cross section is simulated, with a symmetry plane defined along the symmetric boundary. 


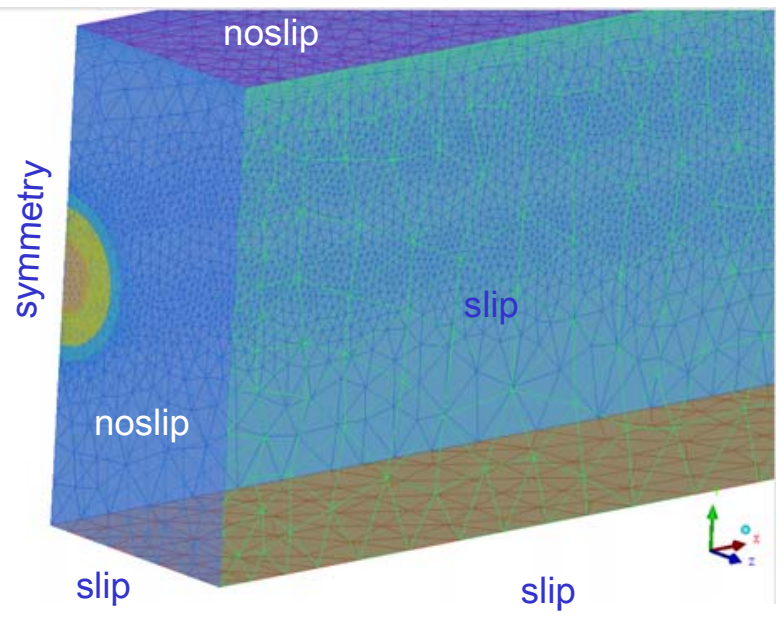

Figure 11. Sample grid and boundary conditions.

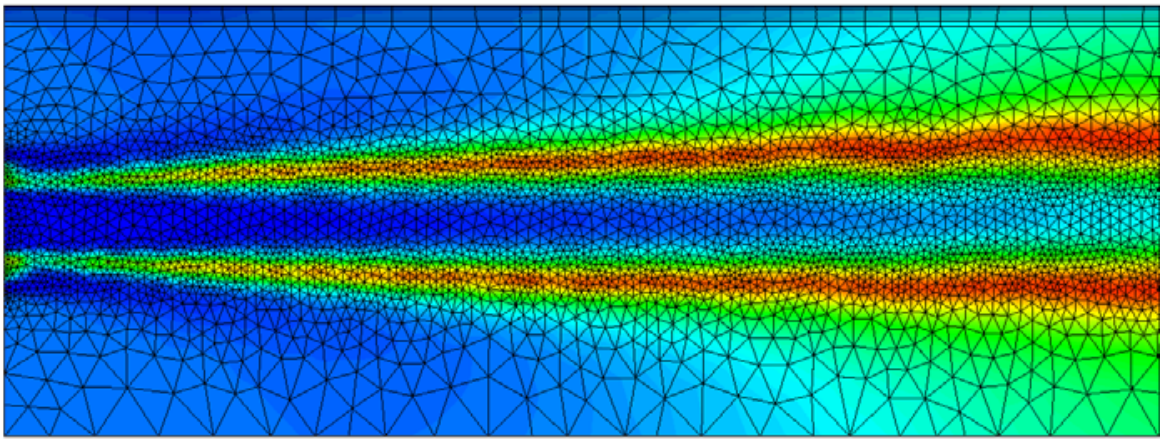

Figure 12. Computational grid along symmetric boundary.

The boundary conditions for all cases are given as shown in Figure 11. In the CFD model, the distance to the wall is held equal to the distance to the inner slip. The purpose of the inner slip boundary is to keep the computational domain approximately symmetric. The remaining boundary conditions are the same as those used in Section IV. A constant temperature of $\mathrm{T}=500 \mathrm{~K}$ was specified along the combustion chamber wall. The injector face and the oxidizer post tip region between the hydrogen and oxygen inlets were set to adiabatic conditions. The nozzle is not included in the CFD model, and a constant pressure condition is specified at the outlet. A constant mass flow rate for hydrogen and a constant mass flow rate for oxygen are specified at the inlets, with gaseous oxygen entering through the center core of the injector and hydrogen entering through the outer annular region.

The effects of modifying the grid resolution were investigated via a grid sensitivity study. The computational grids investigated contained from 23,907 points for the coarse grid 103,628 points for the finest grid. The number of points and smallest grid density used for each grid is given in Table 3, and each grid had a grid distribution as shown in Figure 12. A layer of prism elements were used near the wall so that the turbulence equations could be integrated to the wall without the use of wall functions which might reduce accuracy. The prism layers were constructed with an exponential distribution with an increasing number of prism layers used as the initial wall layer height was decreased. The specifications for the initial height of the prism layers are given in Table 3. 
Table 3. Effect of grid resolution on wall heat flux and combustion length.

\begin{tabular}{ccrrrrr}
\hline $\begin{array}{c}\text { grid } \\
\#\end{array}$ & $\begin{array}{c}\text { grid } \\
\text { points }\end{array}$ & $\begin{array}{c}\text { minimum element size in } \\
\text { shear layer/near wall }(\mathrm{mm})\end{array}$ & $\begin{array}{c}\text { run time } \\
(\mathrm{min})\end{array}$ & $\begin{array}{c}q_{\max } \\
\left(\mathrm{MW} / \mathrm{m}^{2}\right)\end{array}$ & $\begin{array}{c}q_{\text {mean }} \\
\left(\mathrm{MW} / \mathrm{m}^{2}\right)\end{array}$ & $\begin{array}{c}\text { combustion } \\
\text { length }(\mathrm{mm})\end{array}$ \\
\hline 1 & 103628 & $0.15 / 0.03$ & 10920 & 5.41 & 2.11 & 31.1 \\
2 & 72239 & $0.2 / 0.03$ & 3150 & 5.08 & 2.03 & 34.7 \\
3 & 43680 & $0.5 / 0.01$ & 744 & 4.80 & 2.09 & 30.7 \\
4 & 31184 & $0.5 / 0.03$ & 588 & 4.93 & 2.06 & 30.7 \\
5 & 25325 & $0.5 / 0.05$ & 390 & 4.73 & 2.07 & 30.6 \\
6 & 23907 & $1 / 0.03$ & 392 & 4.47 & 2.03 & 23.2 \\
\hline
\end{tabular}
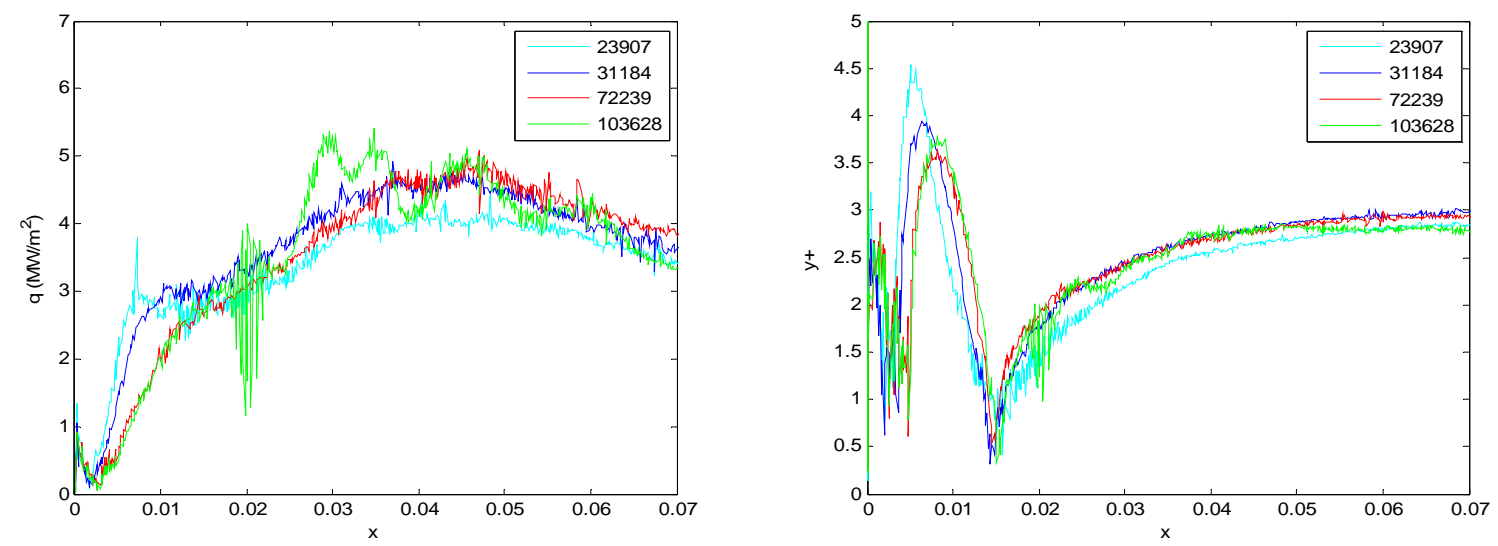

Figure 13. Wall heat flux and $y+$ values for select grids. The distance from the injector face $x$ is given in meters.

The coarsest grid solution (grid 6) predicts a much sharper rise in the wall heat flux that of the fine grid solution (grid 1), and underpredicts the peak heat flux as seen in Figure 13. This indicates that performance could suffer when using a very coarse grid. The largest difference in the results can be seen in the length of the combustion zone in Figure 14. The coarsest grid solution (grid 6) predicts a much shorter combustion zone than the finest grid solution. Using the coarse grid leads to much more smearing along the reaction zone than the two finest grid solutions, grid 1 and grid 2. The species diffuse faster in grid 6 as compared to the grids 1 or 2 . However, the velocity field is less affected by the grid density than the species diffusion. Thus, the mixing that is responsible for convecting heat to the combustion chamber wall leads to heat flux profiles that are less sensitive to grid density. Significant differences are seen in the CFD solutions as the grid resolution is increased to its finest level. Numerical unsteadiness was seen in the finest grid solution (grid 1) shown in Figure 14. For this reason, the peak heat flux recorded for grid 1 is not considered the "true" peak heat flux.

In this case, true grid independency cannot be confirmed. However, there is relative consistency between the values of the peak heat flux, mean heat flux, and combustion length for the intermediate grids. Overall, the intermediate grids with 31,184 nodes and 43,680 nodes provide arguably the best tradeoffs between run time, numerical steadiness, and accuracy as compared with other grid resolutions. A grid with a resolution between that of grids 1 and 2 was used for the CFD modeling study in Section IV. This indicates that significant improvement in the heat flux profile would not necessarily be obtained by increasing the grid resolution.

For the same injector element and mass flow rates used for the grid sensitivity study and for the modeling study, the reduction in the combustion chamber area appears to result in a reduction of the combustion length. However, because of the numerical unsteadiness of the finest grid, it is difficult to determine whether this is due to the combustion chamber geometry, or due to inadequate grid resolution. It is possible that the combustion length may be, for the most part, only a function of the injector geometry and mass flow rate, and not a function of the combustion chamber geometry. The parameter study of Section VI tries to determine some of the geometric effects on injector flow. 

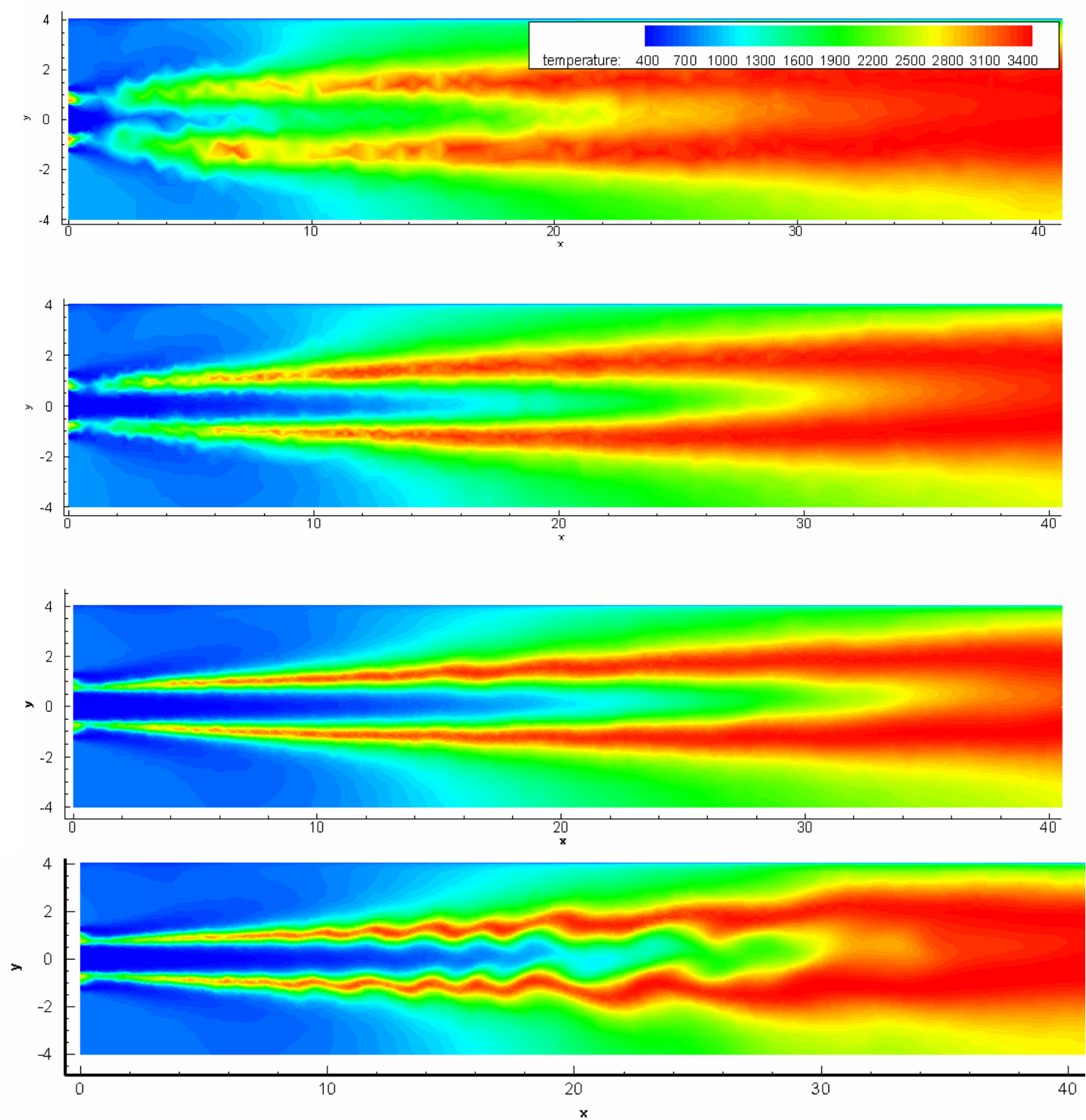

Figure 14. Comparison of temperature $(\mathrm{K})$ contours for grids with 23,907, 31,184, 72,239, and 103,628 points, top to bottom, respectively. The finest grid shows time-dependent oscillations.

\section{Parametric Sensitivity Evaluation}

The parametric sensitivity evaluation explores the effects of geometry on the peak heat flux and combustor length. Approximately $90 \%$ of the heat flux to the combustor wall is due to heat transfer from the outer row of injector elements. The second row of injector elements is responsible for approximately $10 \%$ of heat flux to the wall. This information was used to simplify the computational model of a $\mathrm{GO}_{2} / \mathrm{GH}_{2}$ shear coaxial multi-element injector to make it suitable for a parametric study. The injector face simplification of the full injector shown in Figure 15 is outlined below:

1) For the CFD model, only the outer row of elements is considered. Currently, the effects and interactions of the outer element row with interior elements are simplified by imposing symmetric conditions.

2) Only a single outer element is modeled. The spacing from the injector element to the computational boundaries correspond to the actual radial and circumferential spacing of the full injector

Thus, the CFD model is a scaled down version of what would occur in an actual combustion chamber. The CFD model attempts to capture effects near the outer edge of the injector. 
The variables are the circumferential spacing (number of injector elements in outer row), wherein the total mass flow rate through the outer row injector elements is held constant, and the radial spacing, such that the distance to the wall is held equal to the distance to the inner slip boundary. The purpose of the inner slip boundary is to keep the computational domain approximately symmetric, as the contributions and interactions from inner elements are neglected in the analysis. It is desired that the CFD model be able agree qualitatively with related experiments as well as establish the sensitivity of certain geometry changes on wall heating.

The CFD simulations were conducted using loci-STREAM. ${ }^{20}$ The CFD model attempts to approximate the single-element section near the chamber's outer wall given in Figure 15. The single-element section was approximated using a rectangular shaped computational domain. Only one-half of the domain is simulated. The grid resolution used is equivalent to the intermediate grid 3 from Table 3. This grid was chosen for its balance of accuracy and relatively short run-time. The solutions are expected to give good heat flux accuracy, but the combustion chamber length will be somewhat under-predicted.

a)
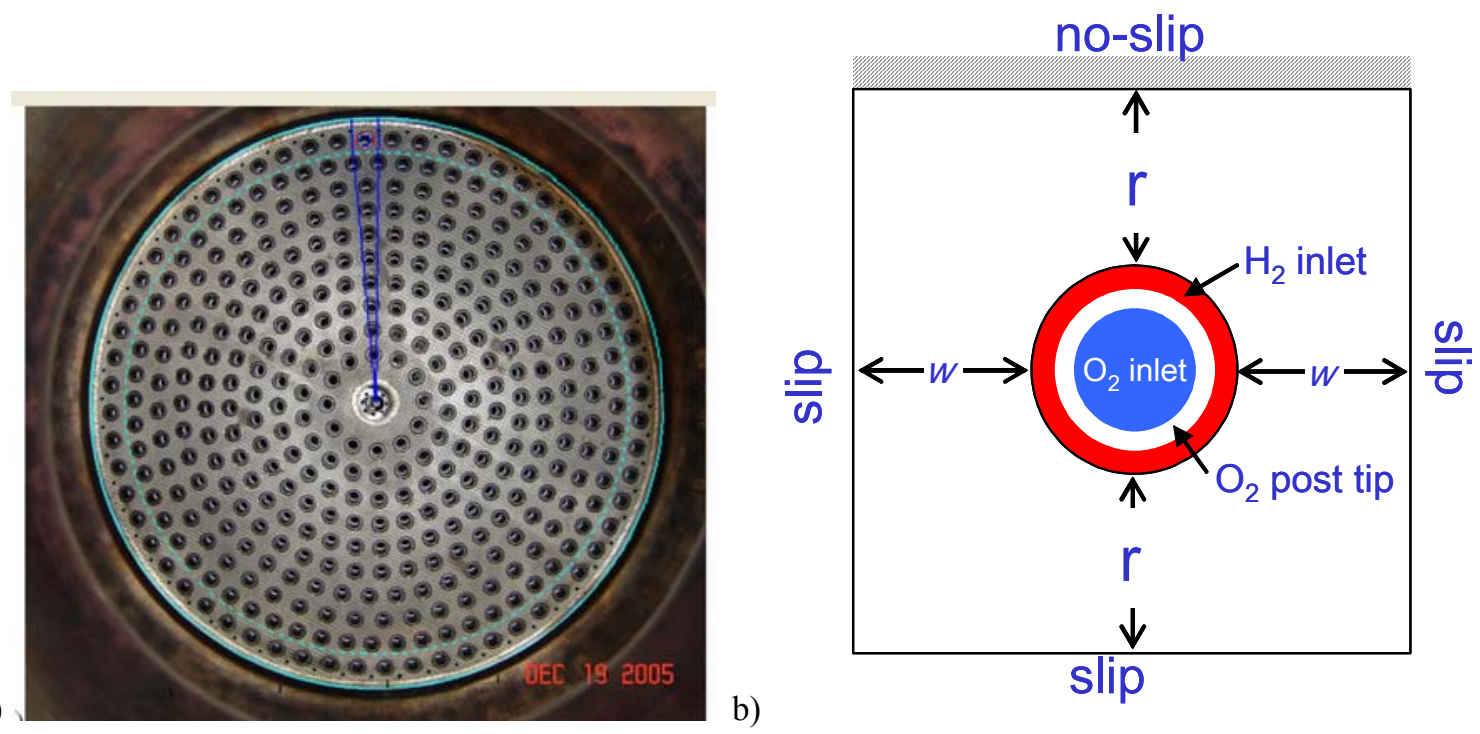

Figure 15. (a) IPD injector and (b) computational domain and boundary conditions on injector element face. One element in the outer element row is simulated. The circumferential spacing $w$ is a function of the number of injector elements in the outer row.

In summary, the parameters are the peak heat flux $q_{\max }\left(N^{*}, r^{*}\right)$ and the combustion length $L_{C}\left(N^{*}, r^{*}\right)$ where the independent variables are explored within the range

$$
\begin{aligned}
& 0.75 \leq N^{*} \leq 1.25 \\
& 0.25 \leq r^{*} \leq 1.25 \\
& N^{*} \leq N_{\max } / N_{\text {baseline }}
\end{aligned}
$$

where

$$
N^{*}=N / N_{\text {baseline }}, r^{*}=r / r_{\text {baseline }}
$$

where $N$ is the number of injector elements, $N_{\max }$ is the maximum possible number of injector elements in the outer row, and $r$ is given as shown in Figure 15. The combustion chamber length is the length at which combustion is $99 \%$ complete, and a shorter combustion length indicates increased performance. A low peak heat flux would reduce the risk of wall burnout. Although the number of injector elements in the outer row changes, the total combined mass flow rate to the outer elements also remains constant, so the mass flow rates for the individual injectors are a function of the number of injector elements $N$. The distance $w$ of the computational domain in Figure 15(b) is given by 


$$
w(N)=R \tan \left(\frac{\pi}{N}\right)-\frac{D}{2}
$$

where $R$ is the distance from the center of the injector to the center of an outer element injector element and $D$ is the injector element diameter.

The baseline injector element geometry is based on the experimental test case RSM-1 by Pennsylvania State University, while the overall injector and element spacing is based on the Integrated Powerhead Demonstrator (IPD) ${ }^{22}$ main injector. For this injector, the maximum number or injector elements $N_{\max }$ allowable in the outer row is 101. The flow conditions and injector geometry for the baseline injector are given in Table 4. The inlet flow represents incompletely burned flow from upstream preburners, so both the fuel and oxidizer contain some water as a constituent.

The design points based on $r^{*}$ and $N^{*}$ are shown in Figure 16. The first seven design points were selected based on a preliminary design sensitivity study. Point 16 lies at the center of the design space. Latin Hypercube Sampling was then used to select the seven remaining design points within the variable ranges.

Table 4. Flow conditions and baseline combustor geometry for parametric evaluation.

\begin{tabular}{lc}
\hline Fuel annulus outer diameter $(\mathrm{mm})$ & 7.49 \\
Fuel annulus inner diameter $(\mathrm{mm})$ & 6.30 \\
Oxidizer post inner diameter $(\mathrm{mm})$ & 5.26 \\
Oxidizer post tip recess $(\mathrm{mm})$ & 0.43 \\
Combustion chamber diameter $(\mathrm{mm})$ & 262 \\
$r_{\text {baseline }}(\mathrm{mm})$ & 6.59 \\
$N_{\text {baseline }}$ & 60 \\
Baseline wedge angle (degrees) & 6.0 \\
Total fuel mass flow rate in outer row $(\mathrm{kg} / \mathrm{s})$ & 1.986 \\
Total oxidizer mass flow rate in outer row $(\mathrm{kg} / \mathrm{s})$ & 5.424 \\
Fuel temperature $(\mathrm{K})$ & 798.15 \\
Oxidizer temperature $(\mathrm{K})$ & 767.59 \\
Chamber pressure $(\mathrm{MPa})$ & 5.42 \\
$\mathrm{H}_{2}$ mass percentage of fuel & 41.3 \\
$\mathrm{H}_{2} \mathrm{O}$ mass percentage of fuel & 58.7 \\
$\mathrm{O}_{2}$ mass percentage of oxidizer & 94.62 \\
$\mathrm{H}_{2} \mathrm{O}$ mass percentage of oxidizer & 5.38 \\
&
\end{tabular}

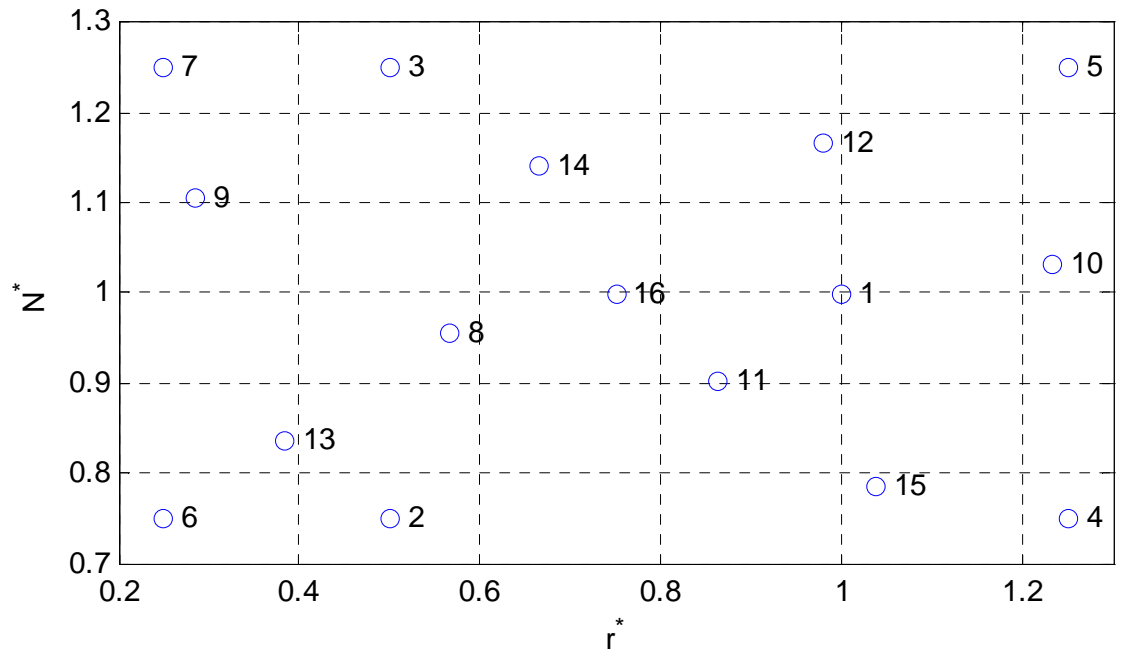

Figure 16. Design points selected for design space sensitivity study. Point 1 indicates the baseline case. 
Figure 17 shows the values of the parameters at each design point. It can be seen that the mean heat flux across the combustion chamber wall stays relatively constant across all of the design points. The maximum heat flux, however, varies depending on the combustor geometry. The design points have an average mean heat flux of $8.2 \mathrm{MW} / \mathrm{m}^{2}$ and an average maximum heat flux of $37.3 \mathrm{MW} / \mathrm{m}^{2}$. In general, as the maximum heat flux becomes lower, the combustion length is longer, indicating slower combustion. For design purposes, there would need to be some balance between the maximum heat flux and combustion chamber length. From Figure 7 (b), it can be seen that case 6 shows good balance between minimizing the peak heat flux and minimizing the combustion chamber length, while case 12 gives arguably the worst characteristics due to its high maximum heat flux and long combustion chamber length. Figure 17 also shows the maximum heat flux and combustion chamber length as a function of the hydrogen mass flow rate. It is apparent that the maximum heat flux is not a function of the mass flow rate alone, but that there must be other influencing factors. There does seem to be an overall decrease in the maximum heat flux with the mass flow rate, as well as an overall increase in combustion chamber length with increasing mass flow rate, which is a function of $N^{*}$. No obvious relationship was seen between the maximum heat flux or combustion chamber length and the cross-sectional area. This indicates that, a smaller cross-sectional area does not automatically translate into a longer combustion chamber length, as one might expect. This was also demonstrated by the grid sensitivity study.

The CFD results for four cases, representing the baseline case along with cases demonstrating good or poor heat flux characteristics, are shown in Figure 18. It can be seen that the flame is flattened somewhat based on the shape of the computational domain. Another major observation is of the location of the recirculation region. Instead of hot gases being directed at the wall, as in the baseline case and case12, the recirculation region of case 2 and case 6 is located between injector elements, and the streamlines are largely parallel to the combustion chamber wall. This led to an observation that all of the CFD solutions resulted in one of two scenarios. Eleven of the cases showed a sharp peak in the wall heat flux near the injector face with the downstream heat flux considerably lower than the peak heat flux. This is termed "Pattern 1," and corresponds to cases that have hot gases directed at the wall as in Figure 19(a). The remaining five cases had a relatively low heat flux near the combustion chamber wall that grew gradually to a slight peak further downstream. This group is termed "Pattern 2," and corresponds to the cases that have a recirculation zone that would exist between injector elements. The two groups can be clearly seen in Figure 20 in the plot of maximum heat flux versus $r^{*}$. Figure 21 shows the heat flux profile and contours for case 12 of Pattern 1, and case 6 of Pattern 2. In Pattern 2, the heat flux is spread across the combustion wall, rather than being localized as were the cases from Pattern 1. The best performing designs with regards to heat flux appear to be those with small distances between the injector and the wall. However, of the cases in Pattern 2, the worst cases are cases 7 and 9 that have smaller domain widths as compared to the other cases. This would suggest that the peak heat flux might be a function of the domain's aspect ratio, rather than separately being a function of radial or circumferential spacing, alone.

The domain's aspect ratio is given by $A R=r^{*} / w^{*}$, where $w^{*}=w / w_{\text {baseline }}$, and $w_{\text {baseline }}$ is determined based on $N$ $=N_{\text {baseline }}$ in Eq. (8). It can be seen in Figure 22 that the value of the peak heat flux appears to be strongly dependent on the aspect ratio. The designs with the lowest peak heat flux also have the lowest aspect ratio. This indicates that it may be desirable to have a low ratio of wall spacing (radial spacing) to injector-injector spacing (circumferential spacing) to reduce the peak heat flux. Due to the presence of case 5, it is difficult to determine whether the cases approximately follow a linear trend and case 5 is an outlier, or if the actual trend is quadratic.

It appears that the peak heat flux is highly sensitive to the combustion chamber geometry as evidenced by Figure 22. The relationship of the combustion length to geometry is less clear. It appears that there is some sensitivity to the geometry due to the fact that equivalent injector elements with equal mass flow rates can result in combustion chamber lengths that can differ significantly (see points 2, 4, and 6 in Figure 17 (d)). However, no clear relationship was observed between the combustion length and the geometric parameters. An individual analysis on a single injector element of the effect of the combustion chamber geometry on combustion length with constant mass flow rate may be necessary to determine the relationship. 

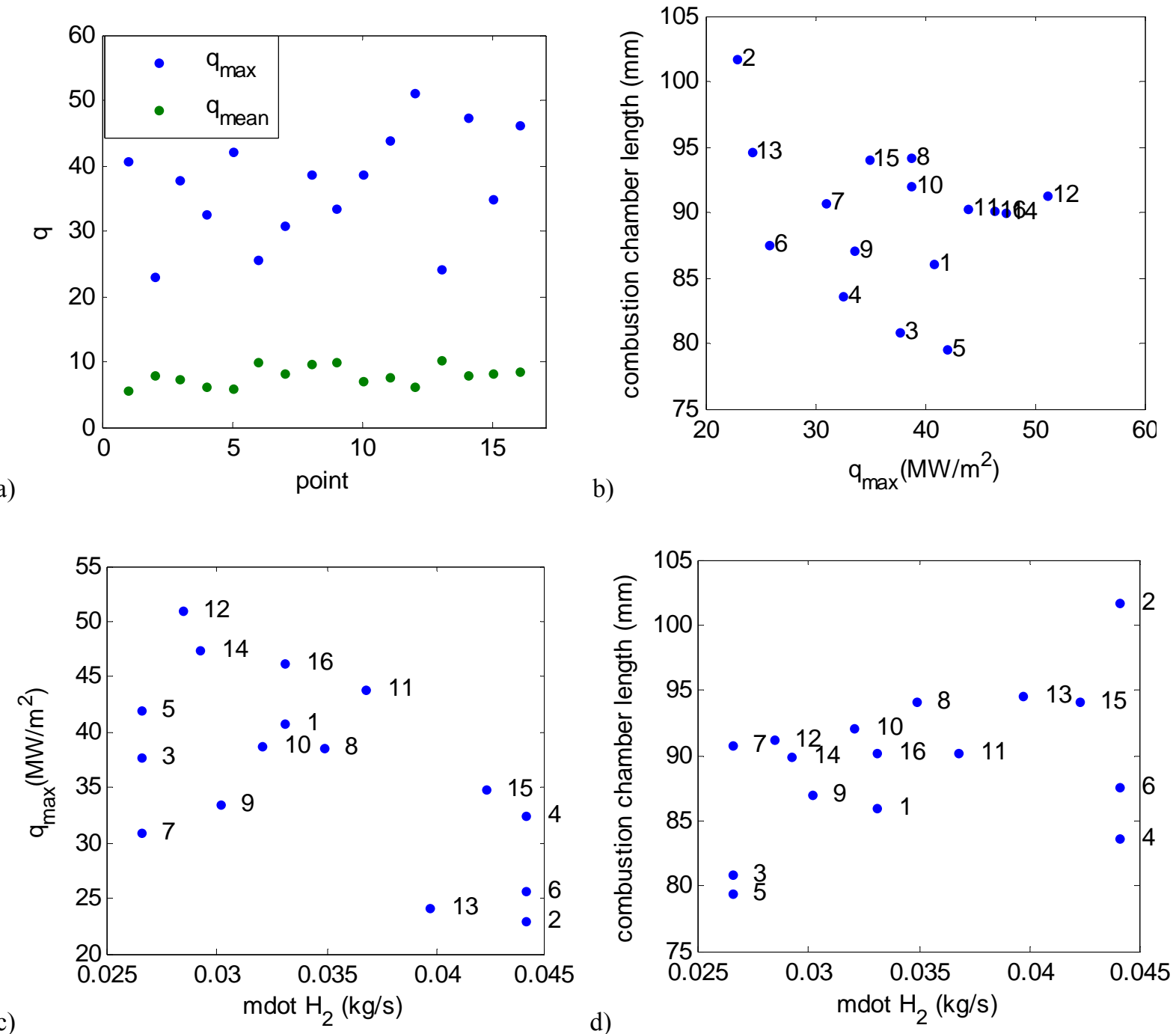

Figure 17. (a) Heat flux and combustion length data for each point, (b) Combustion chamber length versus maximum heat flux, and (c) maximum heat flux and (d) combustion chamber length versus the hydrogen flow rate. 

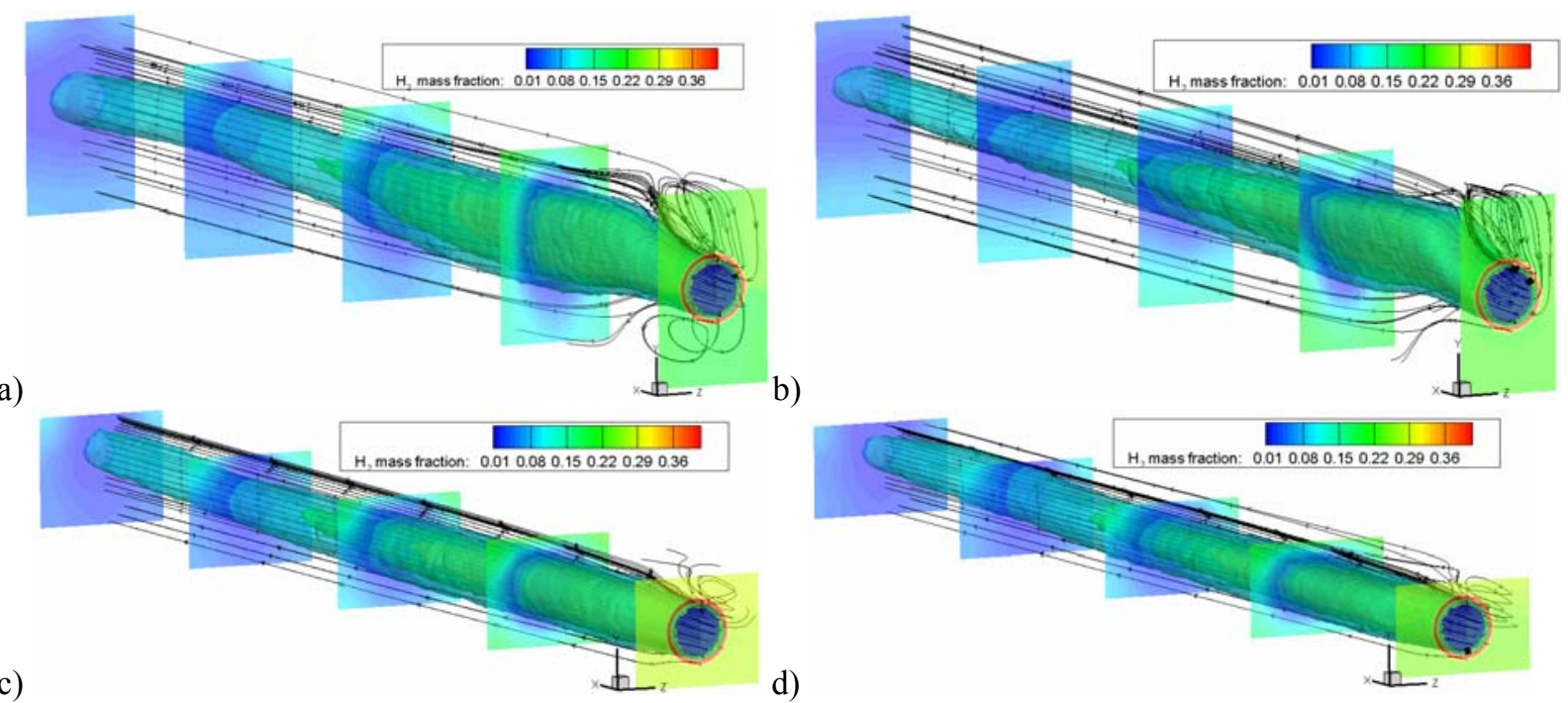

Figure 18. Oxygen iso-surfaces and hydrogen contours for (a) the baseline case (case 1) (b) the worst overall case (case 12), (c) the case with the lowest peak heat flux (case 2), and (d) the best overall case (case 6). The combustion chamber wall is at the top of each figure. Approximately half of the designs showed solutions similar to (a) and (b), while the remainder was similar to (c) and (d). Solutions are mirrored across the z-plane.

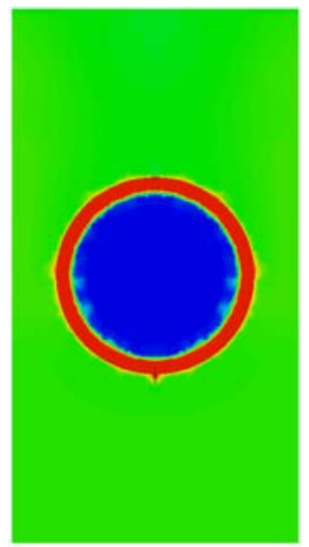

a)

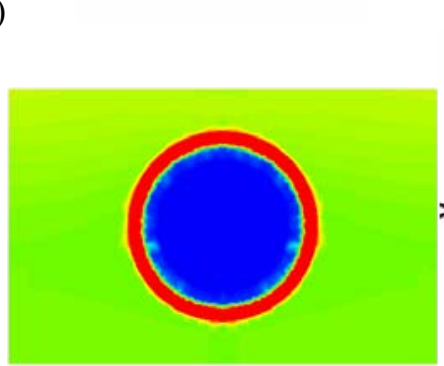

b)

Figure 19. Hydrogen contours and streamlines for (a) case 12 and (b) case 6 . The wall is located at the top of each plot. Case 6 shows the persistence of a gaseous hydrogen layer near the combustion chamber wall. 


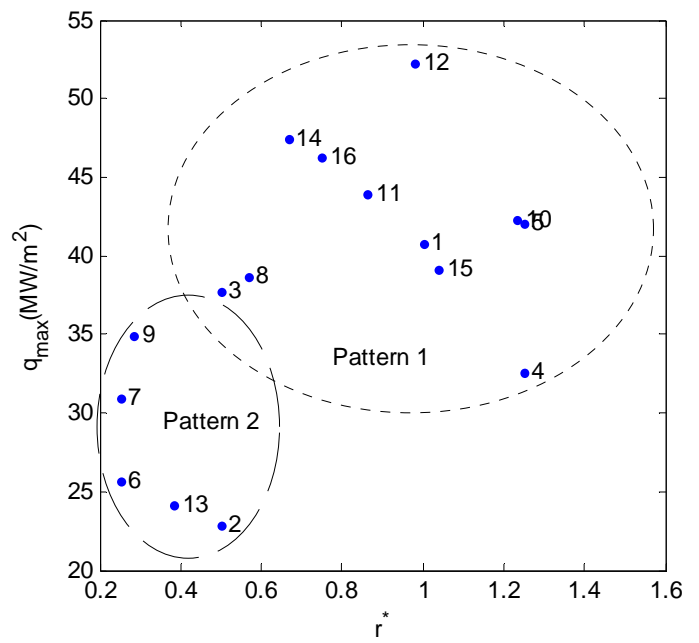

Figure 20. Maximum heat flux for a changing radial distance $r^{*}$. Point 1 is the baseline case.

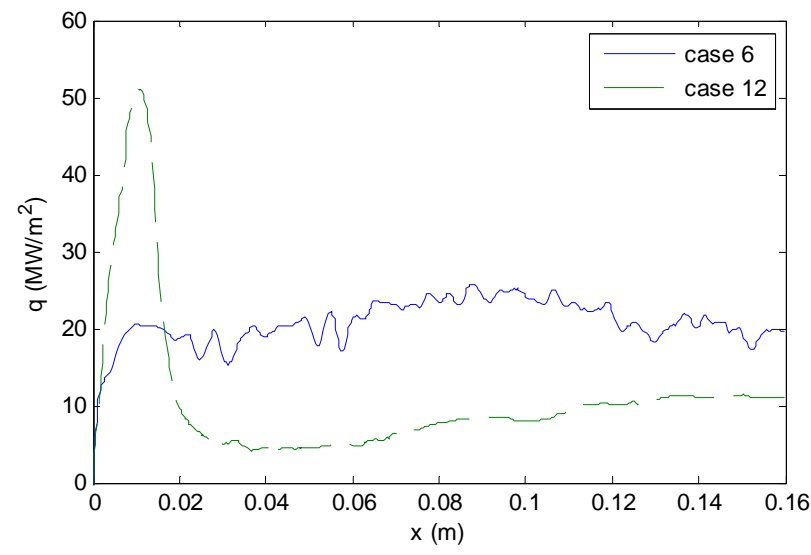

a)

$\mathrm{q}\left(\mathrm{MW} / \mathrm{m}^{2}\right)$
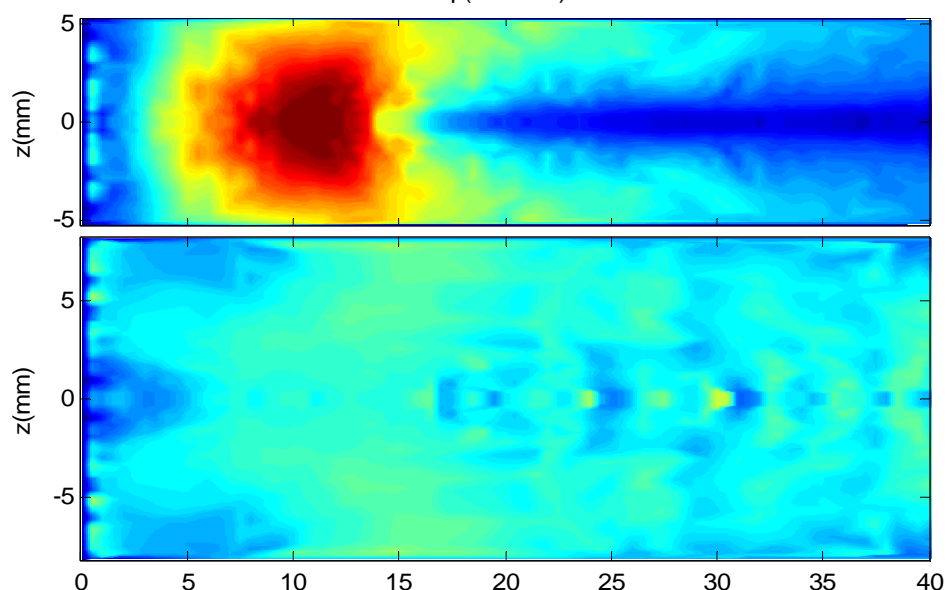

b)

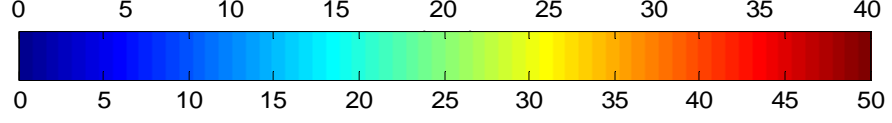

Figure 21. Heat flux distribution along (a) center of combustion chamber wall for case 6 and case 12. (b) Heat flux distribution along first one-third length of entire wall for case 12 (top) and case 6 (bottom). Horizontal axis is $x$-axis. 


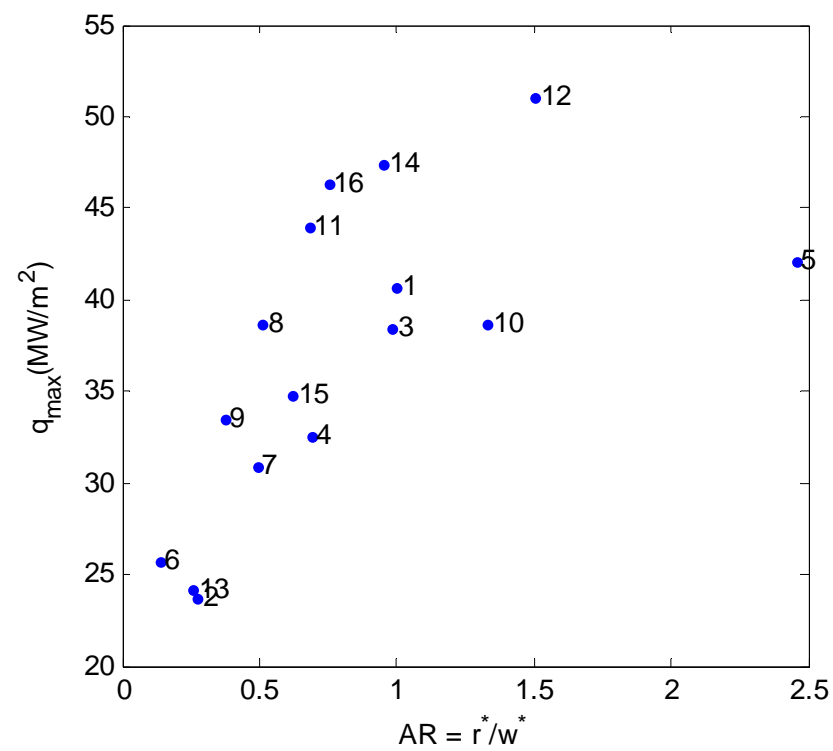

Figure 22. Maximum heat flux as a function of aspect ratio.

\section{Conclusion}

The CFD model was able to qualitatively match the experimental results. Uncertainty exists in the prediction of the peak heat flux and heat rise. However, the predicted location of the peak heat flux was consistent with the experiment. The heat flux downstream of the reattachment point was well predicted. In addition, the CFD results were able to provide additional insight into the combusting flow. In particular, the relationship between the flow dynamics and heat transfer could be characterized. It was found that the effect of the 3-D square geometry shaped the recirculation in a way that noticeably affected the heat transfer profile. The heat flux along the wall is further shaped due to the recirculation of fluid that has had time to cool along the combustion chamber wall, resulting in a relatively cool region of fluid near the injector face. Beyond the reattachment point, the homogenous fluid cools at a relatively constant rate. The heat transfer within the combustion chamber can be characterized via the eddy conductivity which further relates to the peak heat flux at the wall. Additional experimental temperature measurements could improve the CFD modeling process by providing some measure of the 2-D wall heat transfer effects. Additional measurements could also improve the accuracy of the estimated wall heat flux and temperatures.

A grid sensitivity study on the injector element used for the CFD modeling remained inconclusive. A grid independent solution could not be obtained by refining the grid. Numerical unsteadiness resulted with the finest grid. The coarsest grid predicted a sharper heat flux rise, a lower peak heat flux, and a shorter combustion length than the finer grids. With the exception of the coarsest grid and the finest grids, the predicted heat flux remained largely unaffected. This indicates that a finer or coarser grid would likely have little effect of the heat flux predicted in the modeling study. However, the predicted combustion length varied significantly based on the grid resolution. Additional studies would be required to determine the reason for the numerical unsteadiness.

A parameter study was used to determine the effects of combustion chamber geometry on the wall heat flux and combustion length. While it does appear that the combustion length is definitely affected by the geometry, the sensitivity study was not able to reveal the direct relationship between combustion length and geometry. Based on a computational model for an injector element near the combustion chamber wall of a multi-element injector, it was found that an injector element that is located far from the combustion chamber wall does not always result in the best heat transfer characteristics. The results of the parameter study suggest that by increasing the spacing between injector elements of the outer row, while reducing the distance of the outer row to the wall, that the heat transfer results could be better controlled. This configuration helps to direct heat away from the wall, rather than towards it, and results in an even distribution of heat across the combustion chamber wall. To a lesser degree, increasing the distance to the combustion chamber wall can also result in reduced peak heat flux, but the required spacing may possibly be prohibitively large. In the future, further exploration into each phenomenon should provide additional insight. 


\section{Acknowledgments}

This research is performed in coordination with the Institute for Future Space Transport (IFST) under the Constellation University Institute Project (CUIP).

\section{References}

${ }^{1}$ Jones, G., Protz, C., Trinh, H., Tucker, K., Nesman, T., and Hulka, J., "Status of the Combustion Devices Injector Technology Program at the NASA MSFC," 41st AIAA/ASME/ASME/SAE/ASEE Joint Propulsion Conference, AIAA-2005-4530, Tuscon, AZ, July 10-13, 2005.

${ }^{2}$ Hill, P. and Peterson, C., Mechanics and Thermodynamics of Propulsion, Addison-Wesley, 1992, pp. 58, pp. 582.

${ }^{3}$ Dickerson, R., Tate, K., and Nurick, W., "Correlation of spray injector parameters with rocket engine performance," AFRPL-TR-68-11, January, 1968.

${ }^{4}$ Pavli, A. L., "Design and Evaluation of High Performance Rocket Engine Injectors for use with Hydrocarbon Fuels," NASA TM-69319, 1979.

${ }^{5}$ Calhoon, D., Ito, J., Kors, D., "Investigation of gaseous propellant combustion and associated injector/chamber design guidelines," NASA TM-121234, 1973.

${ }^{6}$ Liang, P., Fisher, S., Chang, Y., "Comprehensive modeling of a liquid rocket combustion chamber," Journal of Propulsion, Vol. 2, No. 2, pp. 97- 104, 1986.

${ }^{7}$ Sindir, M. and Lynch, D., "Overview of the state-of-the-practice of computational fluid dynamics in advanced propulsion system design," 28th Fluid Dynamics Conference, AIAA-1997-2124, Snowmass Village, CO, June 29-July 2, 1997.

${ }^{8}$ Tucker, P., Klem, M., Smith, T., Farhangi, S., Fisher, S., Santoro, R., "Design of efficient GO2/GH2 injectors - a NASA, industry and university cooperative effort," $33^{\text {rd }}$ AIAA/ASME/SAE/ASEE Joint Propulsion Conference and Exhibit, Seattle, WA, July 6-9, AAIA-1997-3350, 1997.

${ }^{9}$ Morren, S. H., Myers, R. M., Benko, S. E., Arrington, L. A., and Reed, B. R., “A Laboratory Model of a Hydrogen/Oxygen Engine for Combustion and Nozzle Studies," NASA TM-106281, 1993.

${ }^{10}$ Gill, G. S., "Liquid rocket engine injectors," NASA/SP-8089, 1976.

${ }^{11}$ Rupe, J. and Jaivin, G., "The effects of injection mass flux distributions and resonant combustion on local heat transfer in a liquid-propellant rocket engine,” NASA Technical Report 32-648, 1964.

${ }^{12}$ Farhangi, S., Yu, T., Rojas, L., Sprouse, K., and McKinnon, J., "Gas-Gas Injector Technology for Full Flow Stage Combustion Cycle Application," 35 ${ }^{\text {th }}$ AIAA/SAE/ASME/ASEE Joint Propulsion Conference, June 20-23, Los Angeles, CA, 1999.

${ }^{13}$ Conley, A., Vaidyanathan, A., and Segal, C., "Heat fluxes measurements in a GH2/GO2 single-element, shear injector," AIAA-2006-5048, 42 ${ }^{\text {nd }}$ AIAA/ASME/SAE/ASEE Joint Propulsion Conference and Exhibit, Sacramento, California, July 9-12, 2006.

${ }^{14}$ Foust, M. J., Deshpande, M., Pal, S., Ni, T., Merkle, C. L., Santoro, R. J., "Experimental and analytical characterization of a shear coaxial combusting $\mathrm{GO}_{2} / \mathrm{GH}_{2}$ flowfield," AIAA-96-0646, 34 th AIAA Aerospace Sciences Meeting and Exhibit, Jan 15-18, Reno, NV, 1996.

${ }^{15}$ Cheng, G., Anderson, P., and Farmer, R., "Development of CFD model for simulating gas/liquid injectors in rocket engine design," AIAA-1997-3228, 33 ${ }^{\text {rd }}$ AIAA/ASME/SAE/ASEE Joint Propulsion Conference and Exhibit, Seattle, WA, July 6-9, 1997.

${ }^{16}$ Schley, C., Hagemann, G., Tucker, K. P., Venkateswaran, S., and Merkle, C. L., "Comparison of computational codes for modeling hydrogen-oxygen injectors," AIAA-1997-3302, 33 ${ }^{\text {rd }}$ AIAA/ASME/SAE/ASEE Joint Propulsion Conference and Exhibit, Seattle, WA, July 6-9, 1997.

${ }^{17}$ Schley, C., Hagemann, V., Golovitchev, V., "Comparison of high pressure H2/O2 rocket model engine reference simulations," AIAA-95-2429 AIAA/SAE/ASME/ASEE 31 st Joint Propulsion Conference and Exhibit, Monterey, CA, June 28-30, 1995.

${ }^{18}$ Ivancic, B., Mayer, W., Krülle, G., and Brüggemann, D., "Experimental and numerical investigation of time and length scales in LOX/GH2-rocket combustors," AIAA-99-2211, 35 ${ }^{\text {th }}$ AIAA/ASME/SAE/ASEE Joint Propulsion Conference and Exhibit, June 20-23, 1999, Los Angeles, CA, 1999.

${ }^{19}$ Lin, J., West, J., Williams, R., and Tucker, P., "CFD code validation of wall heat fluxes for a GO2/GH2 single element combustor," AIAA-2005-4524, 41st AIAA/ASME/SAE/ASEE Joint Propulsion Conference, Tucson, AZ, July 10-13, 2005.

${ }^{20}$ Thakur, S. and Wright, J., "Validation of a pressure-based combustion simulation tool for a single element injector test problem," 3rd International Workshop on Rocket Combustion Modeling, Paris, France, March 13-15, 2006.

${ }^{21}$ Wang, T., McConnaughey, P., Warsi, S., and Chen, Y., "Computational Pollutant Environment Assessment from Propulsion System Testing," Journal of Spacecraft and Rockets, Vol. 33, No. 3, May-June 1996, pp.386-392.

${ }^{22}$ Meyer, L., Nichols, J., Jones, J., and Sabol, W., "Integrated Powerhead Demonstrator (booster hydrogen oxygen rocket engines)," AIAA-96-4264, AIAA Space Programs and Technologies Conference, Huntsville, AL, Sept 24-26, 1996. 